\title{
Purkinje Neurons with Loss of STIM1 Exhibit Age-Dependent Changes in Gene Expression and Synaptic Components
}

\author{
Sreeja Kumari Dhanya ${ }^{1,2}$ and ${ }^{(}$Gaiti Hasan $^{1}$ \\ ${ }^{1}$ National Centre for Biological Science, Tata Institute of Fundamental Research, Bangalore, 560065, India, and ${ }^{2}$ Sastra University, \\ Thirumalaisamudram, Thanjavur, Tamil Nadu 613401, India
}

The stromal interaction molecule 1 (STIM1) is an $\mathrm{ER}-\mathrm{Ca}^{2+}$ sensor and an essential component of ER-Ca ${ }^{2+}$ store operated $\mathrm{Ca}^{2+}$ entry. Loss of STIM1 affects metabotropic glutamate receptor 1 (mGluR1)-mediated synaptic transmission, neuronal $\mathrm{Ca}^{2+}$ homeostasis, and intrinsic plasticity in Purkinje neurons (PNs). Long-term changes of intracellular $\mathrm{Ca}^{2+}$ signaling in PNs led to neurodegenerative conditions, as evident in individuals with mutations of the ER-Ca ${ }^{2+}$ channel, the inositol $1,4,5-$ triphosphate receptor. Here, we asked whether changes in such intrinsic neuronal properties, because of loss of STIM1, have an age-dependent impact on PNs. Consequently, we analyzed mRNA expression profiles and cerebellar morphology in PNspecific STIM1 KO mice (STIM1 ${ }^{P K O}$ ) of both sexes across ages. Our study identified a requirement for STIM1-mediated Ca ${ }^{2+}$ signaling in maintaining the expression of genes belonging to key biological networks of synaptic function and neurite development among others. Gene expression changes correlated with altered patterns of dendritic morphology and greater innervation of PN dendrites by climbing fibers, in aging STIM1 ${ }^{P K O}$ mice. Together, our data identify STIM1 as an important regulator of $\mathrm{Ca}^{2+}$ homeostasis and neuronal excitability in turn required for maintaining the optimal transcriptional profile of PNs with age. Our findings are significant in the context of understanding how dysregulated calcium signals impact cellular mechanisms in multiple neurodegenerative disorders.

Key words: calcium signaling; climbing fibers; excitability; mGluR1; motor coordination; RNA-Seq

\section{Significance Statement}

In Purkinje neurons (PNs), the stromal interaction molecule 1 (STIM1) is required for mGluR1-dependent synaptic transmission, refilling of $\mathrm{ER} \mathrm{Ca}^{2+}$ stores, regulation of spike frequency, and cerebellar memory consolidation. Here, we provide evidence for a novel role of STIM1 in maintaining the gene expression profile and optimal synaptic connectivity of PNs. Expression of genes related to neurite development and synaptic organization networks is altered in PNs with persistent loss of STIM1. In agreement with these findings the dendritic morphology of PNs and climbing fiber innervations on PNs also undergo significant changes with age. These findings identify a new role for dysregulated intracellular calcium signaling in neurodegenerative disorders and provide novel therapeutic insights.

Received Sep. 14, 2020; revised Feb. 26, 2021; accepted Mar. 1, 2021.

Author contributions: S.K.D. and G.H. designed research; S.K.D. performed research; S.K.D. analyzed data;

S.K.D. wrote the first draft of the paper; S.K.D. and G.H. edited the paper; S.K.D. and G.H. wrote the paper.

This work was supported by the Department of Biotechnology, Government of India and National Center for Biological Sciences (NCBS), and Tata Institute for Fundamental Research. S.K.D. was supported by Indian Council of Medical Research fellowship. We thank Prof. Anjana Rao (La Jolla Institute for Allergy and Immunology) for providing us with Stim $7^{\text {floxflox }}$ mice; the Animal Facility at NCBS for maintaining the experimental mice; NCBS Central Imaging and Flow Facility for the use of confocal microscope; Next Generation Genomics facility at NCBS for the RNA sequencing; Pragnya Chakraborty for help with RNA-Seq analysis; and Sriram Narayanan (from Dr. V. Thirumalai's laboratory, NCBS) for help with two-photon calcium imaging.

The authors declare no competing financial interests.

Correspondence should be addressed to Gaiti Hasan at gaiti@ncbs.res.in

https://doi.org/10.1523/JNEUROSCI.2401-20.2021

Copyright $\odot 2021$ the authors

\section{Introduction}

Cerebellar Purkinje neurons (PNs) play a key role in coordination of vertebrate movements. They are GABAergic neurons that integrate synaptic inputs from other regions of the brain and cerebellum and generate the sole output of the cerebellar cortex to the deep cerebellar nuclei (Albus, 1971; Ito, 2006; Dean et al., 2010). In several vertebrates studied, such as zebrafish (Namikawa et al., 2019), mouse (Burright et al., 1995; Clark et al., 1997; Watase et al., 2002; Liu et al., 2009; Prestori et al., 2019), and humans (Koeppen, 2005; Koeppen et al., 2013; Rossi et al., 2014; Hekman and Gomez, 2015), PN malfunction leads to deficits in motor function. In humans, the deficits form a spectrum of neurodegenerative disorders called ataxias, characterized by postural instability, gait disturbances, and motor incoordination (Perkins et al., 
2016; K. J. Robinson et al., 2020). An aspect of PN function, somewhat distinct from other neurons, is their strong dependence on intracellular $\mathrm{Ca}^{2+}$ signals through stimulation of the metabotropic glutamate receptor 1 (mGluR1) and intracellular $\mathrm{Ca}^{2+}$ release through ER-resident $\mathrm{Ca}^{2+}$ channel, the inositol 1,4,5-trisphosphate receptor $1\left(\mathrm{IP}_{3} \mathrm{R} 1\right)$. The importance of intracellular $\mathrm{Ca}^{2+}$ signaling in $\mathrm{PN}$ function is well established from a number of studies. Mutants in $m G l u R 1, I P_{3} R 1$, and a $\mathrm{Ca}^{2+}$-binding protein calbindin, display motor deficits (Airaksinen et al., 1997; Ogura et al., 2001; Sugawara et al., 2013). The ER-Ca ${ }^{2+}$ sensor or stromal interaction molecule 1 (STIM1) is also expressed in PNs (Skibinska-Kijek et al., 2009). Previous studies have shown that STIM1 is required for mGluR1-dependent synaptic transmission and the refilling of dendritic ER $\mathrm{Ca}^{2+}$ in PNs (Hartmann et al., 2014). Subsequently, loss of STIM1 in PNs was also demonstrated to regulate their intrinsic excitability, plasticity, and cerebellar memory consolidation (Ryu et al., 2017). To understand how changes in intracellular $\mathrm{Ca}^{2+}$ signaling lead to age-dependent deficits in PN function, as found in the SCAs, here we investigated molecular and cellular changes across a longitudinal time frame in the PNs of mice with cell-specific KO of STIM1. Both in excitable (Mao et al., 2007; Lalonde et al., 2014; Richhariya et al., 2017) and nonexcitable cells (Feske, 2007), loss of STIM1 also affects gene expression. We hypothesized that the loss of STIM1 in PNs may affect the expression of specific genes that contribute to age-dependent deficits in PNs and cerebellar function. Analysis of gene expression profiles from PNs with cell-specific KO of the STIM1 locus demonstrated that STIM1-dependent $\mathrm{Ca}^{2+}$ homeostasis and signaling help maintain the expression of multiple key components of synaptic architecture and function in aging animals. Our findings are significant in the context of finding new therapeutic means of alleviating the neurodegenerative changes associated with human SCAs.

\section{Materials and Methods}

Animals. All experimental procedures were performed in accordance with Institutional Animal Ethics Committee approved by the Control and Supervision of Experiments on Animals (New Delhi, India). All transgenic mice were bred and maintained in the NCBS Animal Facility (Bangalore, India). Conditional $\mathrm{KO}$ using cre-lox system was adopted to generate STIM1 KO exclusively in the PNs. Homozygous Stim 1 flox mice, in which exon 2 of the Stim 1 gene was flanked by loxP sites (OhHora et al., 2008), were bred with mice that express the Cre gene under the control of the PCP2 promoter (B6.129-Tg(Pcp2-cre)2Mpin/J, The Jackson Laboratory, RRID:IMSR_JAX:004146) (Barski et al., 2000) and with a Cre reporter mouse strain Ail4Tdtomato (B6.Cg-Gt(ROSA)

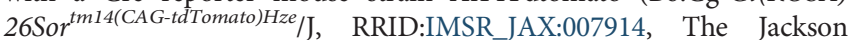
Laboratory). A triple transgenic mouse strain STIM1 $1^{\text {flox/flox; }}$ Ail4Tdtomato ${ }^{\text {td } /+} ; \mathrm{PCP}^{\mathrm{Cre} /+}$ was considered to be PN type-specific STIM1 KO $\left(S T I M 1^{P K O}\right)$ mice, and a double-transgenic strain Ai14Tdtomato ${ }^{\text {td } /+} ; \mathrm{PCP}^{\mathrm{Cre} /+}$ was taken as control. The offspring obtained were genotyped using PCR of genomic DNA extracted from the tail clippings. The WT Stim 1 gene and the floxed Stim 1 gene were detected by the following primer pairs: Stim1-forward, 5'-CGATGGTCTCACGGTCTCTAGTTTC-3'; Stim1-reverse, 5' GGCTCTGCTGACCTGGAACTATAGTG-3' (product length for WT Stim 1: $348 \mathrm{bp}$; product length for floxed Stim 1: $399 \mathrm{bp}$ ) (OhHora et al., 2008). The presence or absence of Cre was detected using the following primers: Cre-forward, 5'-GCCGAAATTGCCAGGATCAG-3'; and Cre-reverse, 5' -AGCCACCAGCTTGCATGATC-3', respectively (product length for Cre: $421 \mathrm{bp}$ ). The Ai14Tdtomato mutant and WT were confirmed using the following primers: Ail4Td wild forward, 5'-AAGGGAGCTGCAGTGGAGTA-3'; Ail4Td wild reverse, 5'-CCGA AAATCTGTGGGAAGTC-3' ${ }^{\prime}$; Ail4Td mutant forward, 5' -CTGTTCCTG
TACGGCATGG-3'; and Ail4Td mutant reverse, 5'-GGCATTAA AGCAGCGTATCC-3' (product length for Ail4Td wild: $297 \mathrm{bp}$, product length for Ai14Td mutant:196 bp). For two-photon calcium imaging, a Cre-dependent, fluorescent, calcium-indicator tool strain (GCaMP6flox/flox $\quad\left(B 6 ; 129 S-G t(R O S A) 26 S\right.$ or $^{\text {tm } 95.1(C A G-G C a M P 6 f) H z e} /$, RRID:IMSR_JAX:024105, The Jackson Laboratory) mice was used. Rosa26-floxed-STOP-GCaMP6f mice were crossed with $\mathrm{PCP}_{2} \mathrm{Cre}$ mice to enable Gcamp6 expression exclusively in the PNs. The double transgenic strain GCaMP6flox/+ $; P C P 2^{\text {Cre/+ }}$ was used as controls and triple transgenic strain Gcamp $6^{\text {flox/+ }} ;$ STIM1 flox/flox $; P C P 2^{\text {Cre/+ }}$ was used as STIM1 KO mice for the two-photon calcium imaging. The GCaMP6f mutant and WT were confirmed using the following primers: GCaMP6f wild forward, 5' - AAGGGAGCTGCAGTGGAGTA-3'; GCaMP6f mutant forward, 5' -ACGAGTCGG ATCTCCCTTTG-3'; and GCaMP6f reverse, 5'-CCGAAAATCTGTGGGAAGTC-3' (product length for GCaMP6f wild: $297 \mathrm{bp}$, product length for GCaMP6f mutant: 450 bp).

Immunohistochemistry. Mice were anesthetized and transcardially perfused with $1 \times$ PBS followed by $4 \%$ PFA in $1 \times$ PBS. Brains were harvested and postfixed with $4 \%$ PFA overnight and then cryoprotected in $30 \%$ sucrose in $1 \times$ PBS. The brain tissue was embedded in $5 \%$ low melting agar and sectioned using a vibratome into $35-\mu \mathrm{m}$-thin sections; 100 $\mu \mathrm{m}$-thickness sections were obtained only for quantification of dendritic arborization. Sections were washed in $1 \times$ PBS, blocked for $1 \mathrm{~h}$ at $4^{\circ} \mathrm{C}$ in $0.1 \%$ Triton $\mathrm{X}-100,5 \%$ normal goat serum, and stained with antibodies overnight at $4^{\circ} \mathrm{C}$ against rabbit anti-STIM1 (1:1000; Cell Signaling Technology, catalog \#5668, RRID:AB_10828699), guinea pig anti-VGLUT2 (1:1000; Synaptic Systems, catalog \#135404, RRID: AB_887884), and rabbit anti-S100B (1:1000; Abcam, catalog \#ab52642, RRID:AB_882426). Sections were washed in PBS-T $(0.1 \%$ Triton $\mathrm{X}-100$ in $1 \times \mathrm{PBS})$ and incubated with suitable secondary antibodies which is coupled to Alexa-488 (goat anti-rabbit AlexaFluor-488, Invitrogen, catalog \#A27034, RRID:AB_2536097 and goat anti-guinea pig AlexaFluor-488, Invitrogen, catalog \#A-11073, RRID:AB_2534117) for $1 \mathrm{~h}$ at room temperature. Slices were washed in $1 \times$ PBS, mounted in Vectashield medium (Vector Labs, catalog \#H-1000), and imaged using an Olympus confocal microscope with FV10-ASW 4.2 viewer software (for Olympus FV1000) or FV31S-SW 2.1 viewer software (for Olympus FV3000).

Confocal imaging and image analysis. Confocal images were obtained using a confocal laser microscope (Olympus FV1000 or FV3000 laser scanning confocal microscope) with a $20 \times$ objective (PlanApo, NA 0.2 ; Nikon), a $40 \times$ objective (PlanApo, NA 1.0; Olympus oil-immersion), or a $60 \times$ objective (PlanApoN, NA 1.42; Olympus oil-immersion). For estimation of STIM1 levels in the PNs, images were acquired at $1.0-\mu \mathrm{m}$ thickness intervals with frame size of $512 \times 512$ pixels. Fluorescence intensity analysis was performed by marking the outlines of PN soma as ROIs using ImageJ. The mean intensity of STIM1 and tdTomato fluorescence was calculated from a minimum of 50-60 PNs in sections from 3 animals of each genotype. For estimation of VGLUT2 puncta along PC dendrites at both proximal and distal ends, Imaris software (Bitplane, version 9.1.2) was used (Kaneko et al., 2011). The Filament Tracer software (Auto Depth) in Imaris was used to trace each dendritic filament keeping the largest diameter threshold as $3 \mu \mathrm{m}$ and thinnest diameter as $1.86 \mu \mathrm{m}$. Spot detection in Imaris software was used to quantify VGLUT2 puncta by setting spot diameter threshold as $2 \mu \mathrm{m}$ and the total distance close to the filament as $3 \mu \mathrm{m}$ in case of proximal dendrites and $2 \mu \mathrm{m}$ in case of distal dendrites. For quantifying the dendritic arborization, confocal images were captured at $1 \mu \mathrm{m}$ intervals from 100 $\mu \mathrm{m}$-thickness sections. Images of primary and secondary dendrites of PNs were analyzed with Filament Tracer (Auto Depth) to measure the total dendritic length, dendritic area, dendritic volume, and number of intersections (Kaneko et al., 2011). Confocal sections with frame size of $1024 \times 1024$ pixels were captured at $0.5 \mu \mathrm{m}$ intervals using $60 \times$ objective for quantifying distal spine density. Filament Tracer (Auto Depth) was used to trace the dendrites by setting the largest diameter as $2 \mu \mathrm{m}$ and minimum endpoint diameter as $0.311 \mu \mathrm{m}$, and spine density was quantified setting the maximum spine length threshold to be $1.5 \mu \mathrm{m}$ (De Bartolo et al., 2015). 
Rotarod test. STIM1 ${ }^{\text {PKO }}$, STIM1 $1^{\text {PHet }}$, and control mice were habituated to the rotarod (IITC, model 775 , Series 8 Software) by providing a short training session where they are subjected to a constant speed of $5 \mathrm{rpm}$ for $400 \mathrm{~s}$. After habituating the mice to the rotarod, mice were tested for four trials a day for 5 consecutive days. In each session, the velocity of the rotation was increased with a constant acceleration of $9 \mathrm{rpm} / \mathrm{min}$ starting from $5 \mathrm{rpm}$ and finally reaching to $45 \mathrm{rpm}$ with a ramp speed at $240 \mathrm{~s}$ (Hartmann et al., 2014). The time at which the mouse fell off the rotarod was recorded, and the mean latency on the rod was calculated for the four trials for each mouse across $5 \mathrm{~d}$ of sessions. The same set of mice were aged and used for the rotarod assay across different ages.

Isolation and culturing of mouse PNs. Cerebellar PNs were isolated and cultured from postnatal P1 mice (Ai14Tdtomato ${ }^{\text {td/+ }} ; \mathrm{PCP}^{\mathrm{Cre} /+}$ and STIM $^{\text {flox/flox }} ;$ Ail4Tdtomato $\left.{ }^{\text {td/+ }} ; \mathrm{PCP}^{\mathrm{Cre} /+}\right)$ as described previously (Tabata et al., 2000). Mice were killed by decapitation, and their cerebella were dissected and washed in $\mathrm{Ca}^{2+}$ and $\mathrm{Mg}^{2+}$-free HBSS containing gentamicin $(10 \mu \mathrm{g} / \mathrm{ml}$ Invitrogen, 15750045). The tissue was dissected in $2.5 \mathrm{ml}$ of HBSS containing trypsin $(0.1 \% \mathrm{w} / \mathrm{v}$; Sigma Millipore, T1426) at $33^{\circ} \mathrm{C}$ for $13-15 \mathrm{~min}$. The cerebella were gently triturated in $2 \mathrm{ml}$ of HBSS supplemented with $\mathrm{MgSO}_{4}-7 \mathrm{H}_{2} \mathrm{O}$ (12 mM) and DNase I (5 U/ml; Sigma Millipore, 11284932001) into small aggregates; $\sim 5 \mathrm{ml}$ of HBBS was added to the cell suspension and centrifuged at $1200 \mathrm{rpm}$ for $5 \mathrm{~min}$ at $4^{\circ}$ C. Supernatant was removed, and the density of dissociated cells was adjusted to $5 \times 10^{6}$ cells $/ \mathrm{ml}$ with DMEM: Nutrient Mixture F-12 (DMEM/F12 Invitrogen, 10565018) supplemented with $\mathrm{N}_{2}$ supplement (Invitrogen, 17502048) and FBS (10\% v/v; Invitrogen, 10270106); $\sim 100 \mu$ l of the suspension was seeded onto the poly-D-lysine-coated coverslip sealed to the plastic culture dish (diameter, $35 \mathrm{~mm}$; Nunc, 153066). After $3 \mathrm{~h}$ of incubation in the $\mathrm{CO}_{2}$ incubator, $2 \mathrm{ml}$ of culture medium was added to each dish. Culture medium used was 1:1 mixture of DMEM/F12 and Neurobasal medium (Invitrogen, 21103-049) supplemented with N-2, B-27 nutrients, and gentamicin $(10 \mu \mathrm{g} / \mathrm{ml}$; Invitrogen, 15750045). The cells were maintained in the $\mathrm{CO}_{2}$ incubator, and half of the old medium was replaced after $3 \mathrm{~d}$ with a fresh one supplemented additionally with BSA $(100 \mathrm{mg} / \mathrm{ml}$; A3156, Sigma Millipore) and a glial proliferation inhibitor, cytosine arabinoside $(4 \mathrm{~mm}$; Sigma Millipore, C1768).

Calcium imaging in PNs. Dissociated PNs were cultured for 14 DIV on poly-D-lysine-coated coverslips. For calcium measurements, the cells were loaded with Fluo-4 acetoxymethylester (Fluo-4 AM; Invitrogen) containing $0.002 \%$ Pluronic-F-127 (Sigma Millipore) in culture medium for $30 \mathrm{~min}$ in the dark (Deb et al., 2016). After incubation, cells were washed with calcium containing HBSS (contains $2 \mathrm{mM} \mathrm{Ca}^{2+}$ ) and placed in $0 \mathrm{Ca}^{2+}$ HBSS (20 mu HEPES, $137 \mathrm{~mm} \mathrm{NaCl}, 5 \mathrm{~mm} \mathrm{KCl}, 2 \mathrm{~mm} \mathrm{MgCl}$, $\mathrm{pH} 7.3$ ) containing $0.5 \mathrm{~mm}$ EGTA and $10 \mathrm{~mm}$ glucose and imaged for $\mathrm{Ca}^{2+}$ changes. Depletion of ER store calcium was initiated by addition of thapsigargin $\left(10 \mu \mathrm{M}\right.$, Invitrogen) in $0 \mathrm{Ca}^{2+} \mathrm{HBSS}$ medium, followed by addition of $2 \mathrm{mM} \mathrm{CaCl}_{2}$ for induction of store-operated $\mathrm{Ca}^{2+}$ entry (SOCE). Fluorescence changes associated with store $\mathrm{Ca}^{2+}$ release and SOCE were recorded every $15 \mathrm{~s}$ for 30 frames. In all experiments, $10 \mathrm{~mm}$ ionomycin (Calbiochem) was added finally to measure maximum fluorescence intensity on complete saturation of dye with calcium. Images were acquired using the Evolution QExi CCD camera attached to a Nikon TE2000 inverted wide-field microscope equipped with $40 \times$ objective lens, using the $488 \mathrm{~nm}$ excitation and $520 \mathrm{~nm}$ emission filter sets. The time lapse acquisition mode of the In Vivo imaging software (Media Cybernetics) was used to follow fluorescence changes over time, and images were quantified using ImageJ. Quantification of SOCE data shown in Figure 5 was from dissociated PNs marked by expression of tdTomato.

Two photon calcium imaging. Parasagittal cerebellar slices of $\sim 250 \mu \mathrm{m}$ were obtained from Purkinje-specific GCaMP6f-expressing mice of 17 weeks old using vibratome (Leica Microsystems, VT1200) following isoflurane anesthesia and decapitation. The slices were sectioned in ice-cold cutting solution containing the following (in $\mathrm{mm}$ ): $87 \mathrm{NaCl}$, $2.5 \mathrm{KCl}, 7 \mathrm{MgCl}_{2}, 0.5 \mathrm{CaCl}_{2}, 1.25 \mathrm{NaH}_{2} \mathrm{PO}_{4}, 26 \mathrm{NaHCO}_{3}, 75$ sucrose, and 10 glucose, bubbled with $95 \% \mathrm{O}_{2}$ and $5 \% \mathrm{CO}_{2}$. The slices were immediately placed in ACSF containing the following (in $\mathrm{mM}$ ): $125 \mathrm{NaCl}$,
$2.5 \mathrm{KCl}, 1 \mathrm{MgCl}_{2}, 2 \mathrm{CaCl}_{2}, 1.25 \mathrm{NaH}_{2} \mathrm{PO}_{4}, 26 \mathrm{NaHCO}_{3}$, and 20 glucose bubbled with $95 \% \mathrm{O}_{2}$ and $5 \% \mathrm{CO}_{2}$. For recovery, slices were incubated at $34^{\circ} \mathrm{C}$ for $45 \mathrm{~min}$ and then kept at room temperature $\left(\sim 22^{\circ} \mathrm{C}\right)$ until imaging.

For two-photon calcium imaging, acute slices were placed in a recording chamber under a custom built two-photon laser scanning microscope equipped with a laser (Coherent Chameleon Ultra II). Microscopes were equipped with $20 \times$ water-immersion objective (Olympus XLUMPLFLN20XW, 1.0 NA). PNs were stimulated with 75 mM KCl or $200 \mu \mathrm{M}$ dihydroxy phenyl glycine (DHPG, Tocris Bioscience, catalog \#0805). An mGluR1 antagonist CPCCOEt (Tocris Bioscience, catalog \#1028) of $200 \mu \mathrm{M}$ was applied to test for the specificity of mGluR1 activation (Hartmann et al., 2008). Images were recorded with frame size of $512 \times 512$ pixels using Scan Image 3.8 and further analyzed using ImageJ.

For quantifying the changes in fluorescence, ROI was drawn around each cell and the fluorescence intensity at each time points was determined. $\Delta \mathrm{F} / \mathrm{F}\left[\Delta \mathrm{F} / \mathrm{F}=\left(\mathrm{F}_{\mathrm{t}}-\mathrm{F}_{\text {basal }}\right) / \mathrm{F}_{\text {basal }}\right]$ was measured for each time point, where $\mathrm{F}_{\mathrm{t}}$ is fluorescence of a particular time point and $\mathrm{F}_{\text {basal }}$ is the fluorescence of the cell when starting the experiment. Data were plotted using the Origin 8.0 software. Peak values of $\Delta \mathrm{F} / \mathrm{F}$ and area under the curve were obtained for every cell, and the data were plotted as histogram. Rate of $\mathrm{Ca}^{2+}$ entry during $\mathrm{KCl}$ stimulation was calculated by computing the average rate of change in fluorescence intensity $(\Delta \mathrm{F})$ between the time at which $\mathrm{F}_{\max }(\Delta \mathrm{F} / \mathrm{F})$ occurs and 11 second time points and expressed as $\Delta \mathrm{F} / \mathrm{t}$.

Microdissection, RNA isolation, and real-time qPCRs. Sagittal slices of the cerebellar vermis of $\sim 250 \mu \mathrm{m}$ thickness were obtained from 1year-old and 14-week-old mice. Cerebellar slices were micro-dissected into Purkinje neuronal layer (PNL) with molecular layer (ML) and granular neuronal layer (GNL) with white matter under an illuminated stereomicroscope (Ryu et al., 2017).

RNA was isolated from PNL with ML and GNL with white matter using Trizol according to the manufacturer's protocol. Tissue was homogenized in $500 \mu \mathrm{l}$ TRIzol (Invitrogen, catalog \#15596026) using micropestle homogenizer followed by vortexing the sample before proceeding with RNA isolation protocol. Purity of the isolated RNA was checked by a NanoDrop spectrophotometer (Thermo Fisher Scientific), and its integrity was detected by running it on a $1 \%$ Tris-EDTA agarose gel; $\sim 500 \mathrm{ng}$ of total RNA isolated was used per sample for cDNA synthesis. For the DNase treatment, a reaction volume of $22.1 \mu \mathrm{l}$ containing $500 \mathrm{ng}$ of isolated RNA, $0.5 \mathrm{U}$ of DNase I (amplification grade), $1 \mathrm{~mm}$ DTT, and $20 \mathrm{U}$ of RNase inhibitor (RNase OUT) was incubated at $37^{\circ} \mathrm{C}$ for $30 \mathrm{~min}$ followed by heat inactivation at $70^{\circ} \mathrm{C}$ for $10 \mathrm{~min}$. cDNA synthesis was initiated for the DNase-treated sample to which is added 200 $\mathrm{U}$ of Moloney murine leukemia virus reverse transcriptase, $50 \mu \mathrm{M}$ random hexamers, and $1 \mathrm{~mm}$ deoxyribonucleotide triphosphate in a final volume of $20 \mu$ l. The reaction mixture was subjected to $25^{\circ} \mathrm{C}$ for $10 \mathrm{~min}$ followed by treatment at $42^{\circ} \mathrm{C}$ for $60 \mathrm{~min}$, and finally heat inactivation at $70^{\circ} \mathrm{C}$ for $10 \mathrm{~min}$. All reagents used were purchased from Invitrogen.

Real-time qPCRs were performed using the KAPA SYBR FAST qPCR kit (Sigma Millipore, catalog \#KK4601) on an ABI 7500 Fast machine (Applied Biosystems) operated with ABI 7500 software version 2 in a total volume of $10 \mu \mathrm{l}$. Primers were designed by using Primer 3 (http://bioinfo.ut.ee/primer3-0.4.0/). Sequences of primers for all set of genes are listed in Table 1. The fold change of gene expression of STIM1 ${ }^{\mathrm{PKO}}$ relative to $\mathrm{WT}$ was normalized according to the $2^{-\Delta \Delta \mathrm{Ct}}$ method where $\Delta \Delta \mathrm{Ct}=[\mathrm{Ct}$ (target gene $)-\mathrm{Ct}(\mathrm{GAPDH}) \mathrm{STIM} 1^{\mathrm{PKO}}$ (Ct (target gene) - Ct (GAPDH)] STIM1 ${ }^{\text {WT }}$.

Western blots. Microdissected PNL and ML were homogenized in $1 \times$ cell lysis buffer (RIPA buffer, Sigma Millipore, catalog \#R0278) containing protease inhibitor cocktail (Sigma Millipore, catalog \#P8340) and phosphatase inhibitors (Cell Signaling Technologies, catalog \#58705) using micropestle homogenizer. The homogenized tissues were centrifuged at $12,000 \mathrm{rpm}$ for $10 \mathrm{~min}$ at $4^{\circ} \mathrm{C}$, and the supernatant was collected as the total cell lysate. Protein quantity of the cell lysate was estimated by the Bradford assay, and an equal amount of protein was loaded onto SDS-PAGE $8 \%-12 \%$ acrylamide gels. Proteins were transferred onto nitrocellulose membrane and blocked using 5\% skim milk in TBS-T 
(TBS with $0.1 \%$ Tween 20) for an hour at $37^{\circ} \mathrm{C}$. Blots were then incubated overnight with primary antibodies at $4^{\circ} \mathrm{C}$. The primary antibodies used were rabbit anti-STIM1 (1:1000; CST, catalog \#D88E10) and mouse anti- $\beta$-actin (loading control) at 1:3000 (BD Biosciences, catalog \#612656). After washing with PBS-T, blots were then incubated for $1 \mathrm{~h}$ with secondary antibodies. The secondary antibodies used were antimouse HRP (1:3000; Cell Signaling Technology, catalog \#7076, RRID: AB_330924) and anti-rabbit HRP (1:3000; Thermo Fisher Scientific, catalog \#32260, RRID:AB_1965959). Bands were visualized with a chemiluminescence detection kit (ECL, Thermo Fisher Scientific, catalog \#32109) and captured using a chemiluminescent detection system (ImageQuant LAS 4000, GE Healthcare) with Image Quant software.

Library preparation, sequencing, and RNA-Seq data analysis. RNA isolated from the PNL together with the ML was run on a Bio-analyzer chip (Agilent Technologies, catalog \#5067-1511) to ensure integrity; $\sim 500 \mathrm{ng}$ of total isolated RNA with an average RIN of 8.2 was used per sample to prepare libraries using TruSeq mRNA Library Prep Kit (Illumina, catalog \#20020594) following the manufacturer's instructions. The prepared libraries were run on a DNA chip (Agilent Technologies, catalog \#5067-4626) in the bio-analyzer to check for their size followed by its quantification using qPCR. The libraries were then run on an Illumina HiSeq 2500 platform using single end and $50 \mathrm{bp}$ read protocol (NGS Facility, NCBS). Six samples were run in a single lane, and biological triplicates were performed for each sample consisting of RNA isolated from WT PNs (with ML) and STIM1 KO PNs (with ML).

More than 60 million reads were obtained per sample with a uniform distribution of reads across samples. FASTQ sequencing reads obtained were aligned to the annotated UCSC Mus musculus mm10 (GRCm38/ mm10) using Tophat (version 2.0.13) (Trapnell et al., 2009). Read counts for each transcript or exon were calculated using the Python-based package HTSeq (version 0.9.1) (Anders et al., 2015). Differential expression on STIM1 KO was estimated by using two R-based Bioconductor software packages: DESeq (RRID:SCR_000154) (Anders and Huber, 2012) and EdgeR (RRID:SCR_000154, empirical analysis of digital gene expression in R) (Anders and Huber, 2010; M. D. Robinson et al., 2010) that analyze the read counts per transcript per sample and normalize them before using an exact test to identify differentially expressed genes using a negative binomial model (Anders and Huber, 2010; Seyednasrollah et al., 2015). DESeq package uses a Relative Log Expression normalization strategy (Anders and Huber, 2010; Anders et al., 2013; Love et al., 2014), and EdgeR package uses Trimmed Mean of M values normalization (M. D. Robinson and Oshlack, 2010; M. D. Robinson et al., 2010). In both the differential analysis methods, $p<$ 0.05 was set as cutoff. Genes that are found to be significantly altered by both DEseq and EdgeR analysis methods were considered further. FunRich (Functional enrichment analysis tool) (Pathan et al., 2015) was used to compare significantly altered gene lists from DESeq and EdgeR, and to generate Venn diagrams keeping mouse genome as the background gene set. Volcano plot was plotted using $\mathrm{R}$ package (version 3.3.3), and heat maps were generated using HemI (Heatmap Illustrator, version 1.0.3.7) (Deng et al., 2014). Gene enrichment analysis and visualization of the Gene Ontology (GO) network were performed using Metascape (http://metascape.org) using parameters specific for Mus musculus with $p$ value cutoff as 0.01 , count threshold at 3 , and minimum enrichment as 1.5. Significantly enriched GO terms for biological process, molecular, cellular component, KEGG pathways, and Reactome have been plotted as bar graphs.

Experimental design and statistical analysis. Mice of both sexes were used for experiments. Statistical analysis was performed using Origin 8.0 software, GraphPad Prism 7.0, or R package. The statistical methods used in each experiment are described in the figure legends. All bar graphs and dot plots show mean \pm SEM, and differences were considered as significant for $p<0.05$, highly significant for $p<0.01$ and $p<0.001$ as determined using the paired Student's $t$ test or a two-way ANOVA for multiple measurements. For rotarod test, two-way ANOVA, followed by Sidak's or Tukey's multiple comparison test, was used for comparisons between groups, and $p<0.05, p<0.001$, and $p<0.0001$ were considered. Tukey's multiple comparison test was used for comparing the significance between the mean latency on the rod for
Table 1. Primers used for real-time $\mathrm{qPCR}^{a}$

\begin{tabular}{|c|c|c|}
\hline$\overline{\text { Gene }}$ & Forward $\left(5^{\prime}-3^{\prime}\right)$ & Reverse $\left(5^{\prime}-3^{\prime}\right)$ \\
\hline Pcp2 & CCAGGCCAGAACCCAGAAAG & CCCAGGTCGTTTCTGCATTC \\
\hline Stim1 & ACAACTGGACTGTGGATGAGG & TGGTTACTGCTAGCCTTGGC \\
\hline Gabra6 & TGCTGGAAGGCTATGACAACC & GTCTGGCGGAAGAAAACATCC \\
\hline Itpr1 & TGAAGGGGAACAGAACGAGC & AGGCCGATTCTTTGTTTCTGC \\
\hline Pvalb & ATGGGGACGGCAAGATTGG & GCGAGAAGGACTGAGATGGG \\
\hline Calm1 & СGTTCTTCCTTCCTTCGCTCG & TTCCTTGGTTGTGATGGTGCC \\
\hline Orai3 & CCTGTGGCCTGGTTTTTATC & GTGCCCGGTGTTAGAGAATG \\
\hline $\operatorname{Cas} q 2$ & AGCCCAACGTCATCCCTAAC & AGTCGTCTTCTCCTGTAGTCC \\
\hline $5100 b$ & GATGTCTTCCACCAGTACTCCG & AGCGTCTCCATCACTTTGTCC \\
\hline Cacng5 & CTTCCTGTGATGTGAGGGCG & CAAAAGTTGGAGTCGAGCGC \\
\hline Atp1a3 & CTGCCGACATGATTCTGCTGG & AGGAAGGGTGTGATCTCAGGG \\
\hline Kctd17 & GGCTCCTCCTACAACTATGGG & GGAGGGAGAAAAGGTTAGGGG \\
\hline Syt11 & CAAGAGGAACATTCAGAAGTGC & CCTGAGAGACCGGTGATATCC \\
\hline Vamp1 & CCCGTCTCGTTGCATTCTCC & GTCATGTTGGGAGGAGGACC \\
\hline Dlg4 & ACCAAGATGAAGACACGCCC & TTCCGTTCACATATCCTGGGG \\
\hline Robo2 & CTGCCATCTAGACCTGACTCC & ACGAGATCCTTGACCTTGCC \\
\hline Gigyf2 & GGACCGCAGTGTTAAAAAGACC & TCTGCTGCCATTCTTCTCCG \\
\hline Map4 & AGCCAGGTTGAAGGTATCCC & TGGCTGCTCTGATAATCCGG \\
\hline $\operatorname{Tfap} 2 b$ & TCAATGCATCTCTCCTGGGC & TGAACAGCTTCCCCTTCTACC \\
\hline Setd 6 & TGGTTTTGCTGAGCCCTATCC & ССССТАCСATCTCCTGTTTGC \\
\hline Bad & GGGGAGCAACATTCATCAGC & САТСССТTСАТССТССТСGG \\
\hline Insr & TTCTAAAGATCCGCCGCTCC & GTTGTGTTTGCTCCAGTCCC \\
\hline Gapdh & CTTTGGCATTGTGGAAGGGC & TGCAGGGATGATGTTCTGGG \\
\hline
\end{tabular}

${ }^{a}$ Sequences of primers for all set of genes for validation using qRT-PCR. Primers were designed using Primer 3 (http://bioinfo.ut.ee/primer3-0.4.0/). Pcp2, Purkinje cell protein 2; Stim1, stromal interaction molecule 1; Gabra6, GABA type A receptor subunit alpha6; Itpr1, inositol 1,4,5-trisphosphate receptor 1; Pvalb, parvalbumin; Calm1, calmodulin1; Casq2, calsequestrin 2; Cacng5, calcium voltage-gated channel auxiliary subunit $\gamma 5$; Atp1a3, ATPase $\mathrm{Na}^{+} / \mathrm{K}^{+}$transporting subunit $\alpha 3 ; \mathrm{Kctd} 17$, potassium channel tetramerization domain containing 17; Syt11, synaptotagmin 11; Vamp1, vesicle-associated membrane protein 1; Dlg4, discs large homolog 4; Robo2, roundabout guidance receptor 2; Gigyf2, GRB10-interacting GYF protein 2; Map4, microtubule-associated protein 4; Tfap2b, transcription factor AP-2 $\beta$; Setd6, SET domain containing 6; Bad, Bclllassociated agonist of cell death; Insr, insulin receptor; Gapdh, glyceraldehyde 3-phosphate dehydrogenase.

Table 2. Fold changes in mRNA on STIM1 KO in PNs ${ }^{a}$

\begin{tabular}{|c|c|c|c|c|c|c|}
\hline \multirow[b]{2}{*}{ Gene } & \multicolumn{4}{|l|}{14 weeks } & \multicolumn{2}{|l|}{1 year } \\
\hline & STIM1 $1^{W T}$ & STIM1 PKO & $p$ & STIM1WT & STIM1 $1^{\text {PKO }}$ & $p$ \\
\hline Itpr1 & $1.02 \pm 0.09$ & $0.92 \pm 0.05$ & 0.38765 & $1.01 \pm 0.08$ & $0.71 \pm 0.09^{*}$ & 0.03393 \\
\hline Pvalb & $1.01 \pm 0.06$ & $0.91 \pm 0.05$ & 0.22470 & $1.01 \pm 0.05$ & $0.68 \pm 0.05^{* * *}$ & 0.00098 \\
\hline Calm1 & $1.04 \pm 0.14$ & $1.03 \pm 0.14$ & 0.98871 & $1.02 \pm 0.08$ & $0.64 \pm 0.14^{*}$ & 0.04656 \\
\hline Orai3 & $1.03 \pm 0.11$ & $0.81 \pm 0.11$ & 0.19959 & $1.00 \pm 0.02$ & $0.80 \pm 0.04^{* *}$ & 0.00596 \\
\hline Casq2 & $1.03 \pm 0.11$ & $1.21 \pm 0.13$ & 0.29986 & $1.02 \pm 0.09$ & $0.73 \pm 0.06^{*}$ & 0.02960 \\
\hline S100b & $1.02 \pm 0.09$ & $0.78 \pm 0.10$ & 0.10524 & $1.01 \pm 0.06$ & $0.70 \pm 0.11^{*}$ & 0.04868 \\
\hline Cacng5 & $1.04 \pm 0.12$ & $1.16 \pm 0.15$ & 0.54134 & $1.01 \pm 0.06$ & $0.81 \pm 0.05^{*}$ & 0.03345 \\
\hline Atp1a3 & $1.01 \pm 0.04$ & $0.92 \pm 0.06$ & 0.30635 & $1.00 \pm 0.04$ & $0.77 \pm 0.09^{*}$ & 0.04507 \\
\hline Kctd17 & $1.04 \pm 0.13$ & $1.15 \pm 0.12$ & 0.56564 & $1.01 \pm 0.09$ & $0.77 \pm 0.05^{*}$ & 0.03983 \\
\hline Syt11 & $1.02 \pm 0.09$ & $0.89 \pm 0.06$ & 0.28322 & $1.01 \pm 0.08$ & $0.80 \pm 0.05^{*}$ & 0.04942 \\
\hline Vamp1 & $1.06 \pm 0.19$ & $0.87 \pm 0.09$ & 0.37641 & $1.02 \pm 0.06$ & $0.65 \pm 0.13^{*}$ & 0.04647 \\
\hline Dlg4 & $1.04 \pm 0.12$ & $0.79 \pm 0.07$ & 0.12287 & $1.01 \pm 0.08$ & $0.77 \pm 0.06^{*}$ & 0.03421 \\
\hline Robo2 & $1.05 \pm 0.14$ & $0.79 \pm 0.15$ & 0.24889 & $1.01 \pm 0.08$ & $0.75 \pm 0.08^{*}$ & 0.04005 \\
\hline Gigyf2 & $1.01 \pm 0.07$ & $1.24 \pm 0.07$ & 0.04737 & $1.00 \pm 0.06$ & $0.83 \pm 0.05^{*}$ & 0.04587 \\
\hline Map4 & $1.04 \pm 0.13$ & $1.06 \pm 0.15$ & 0.94084 & $1.01 \pm 0.07$ & $0.83 \pm 0.03^{*}$ & 0.04470 \\
\hline $\operatorname{Tfap} 2 b$ & $1.09 \pm 0.22$ & $1.06 \pm 0.16$ & 0.88493 & $1.01 \pm 0.06$ & $0.79 \pm 0.07^{*}$ & 0.04835 \\
\hline Setd 6 & $1.02 \pm 0.08$ & $0.90 \pm 0.07$ & 0.32807 & $1.01 \pm 0.09$ & $0.59 \pm 0.08^{* *}$ & 0.00651 \\
\hline$D d x 17$ & $1.03 \pm 0.11$ & $0.87 \pm 0.04$ & 0.21657 & $1.01 \pm 0.07$ & $0.79 \pm 0.06^{*}$ & 0.04358 \\
\hline Bad & $1.04 \pm 0.13$ & $0.91 \pm 0.09$ & 0.47290 & $1.00 \pm 0.04$ & $1.25 \pm 0.09^{*}$ & 0.04716 \\
\hline Insr & $1.03 \pm 0.10$ & $1.19 \pm 0.06$ & 0.22536 & $1.00 \pm 0.05$ & $1.16 \pm 0.04 *$ & 0.03543 \\
\hline
\end{tabular}

${ }^{a}$ The fold changes of the indicated genes from biologically significant pathways in WT and STIM1 KO conditions of 14-week- and 1-year-old mice. All measurements are done by qRT-PCR. Fold changes are normalized to WT levels (reference gene, GAPDH) $(n=6)$. Data are mean \pm SEM.

${ }^{*} p<0.05 ;{ }^{* *} p<0.01 ;{ }^{* * *} p<0.001$; two-tailed Student's $t$ test.

STIM1 ${ }^{\text {WT }}$, STIM1 ${ }^{\text {PHet }}$, and STIM1 ${ }^{\text {PKO }}$ mice, and Sidak's multiple comparison test was used for comparison between STIM1 $1^{W T}$ and STIM1 $1^{\text {PKO }}$ mice.

Data availability. The RNA-Seq data associated with this manuscript has been submitted to GEO with accession number GSE158513. 
A

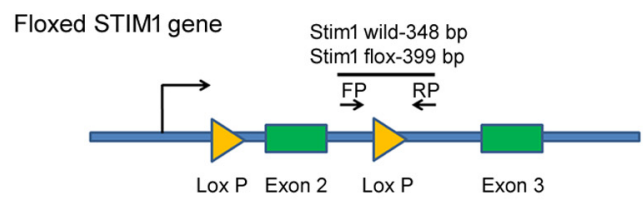

Al14 reporter in Rosa26 locus

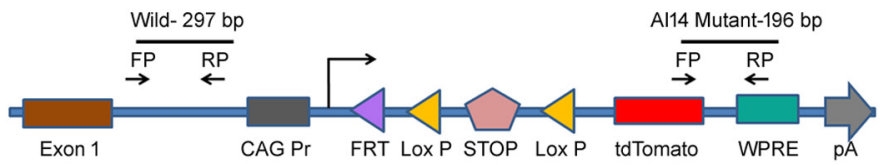

PCP2 gene with Cre recombinase

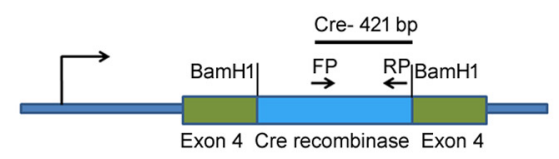

B
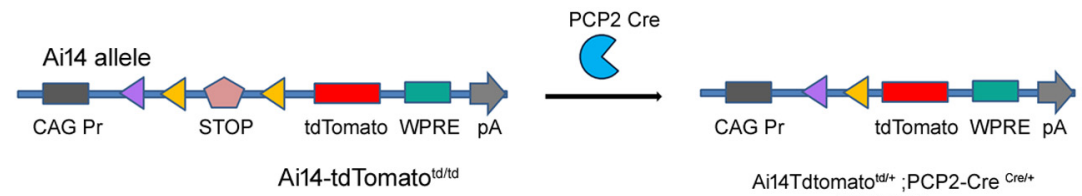

Ai14Tdtomatoto/t+PCP2-Cre cre/t+ $^{\text {to }}$ $\left(\mathrm{STIM} 1^{\mathrm{WT}}\right)$
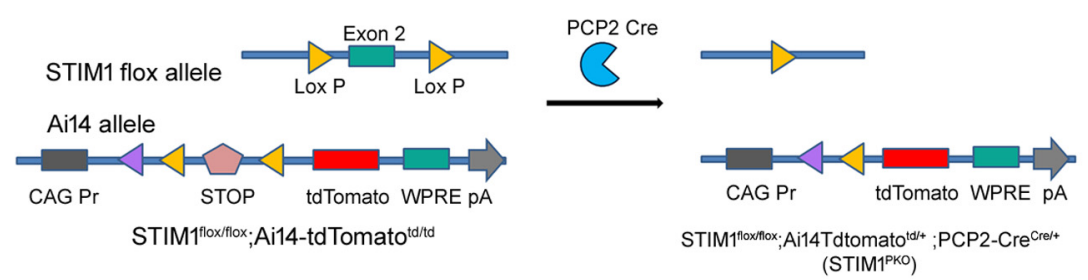

C
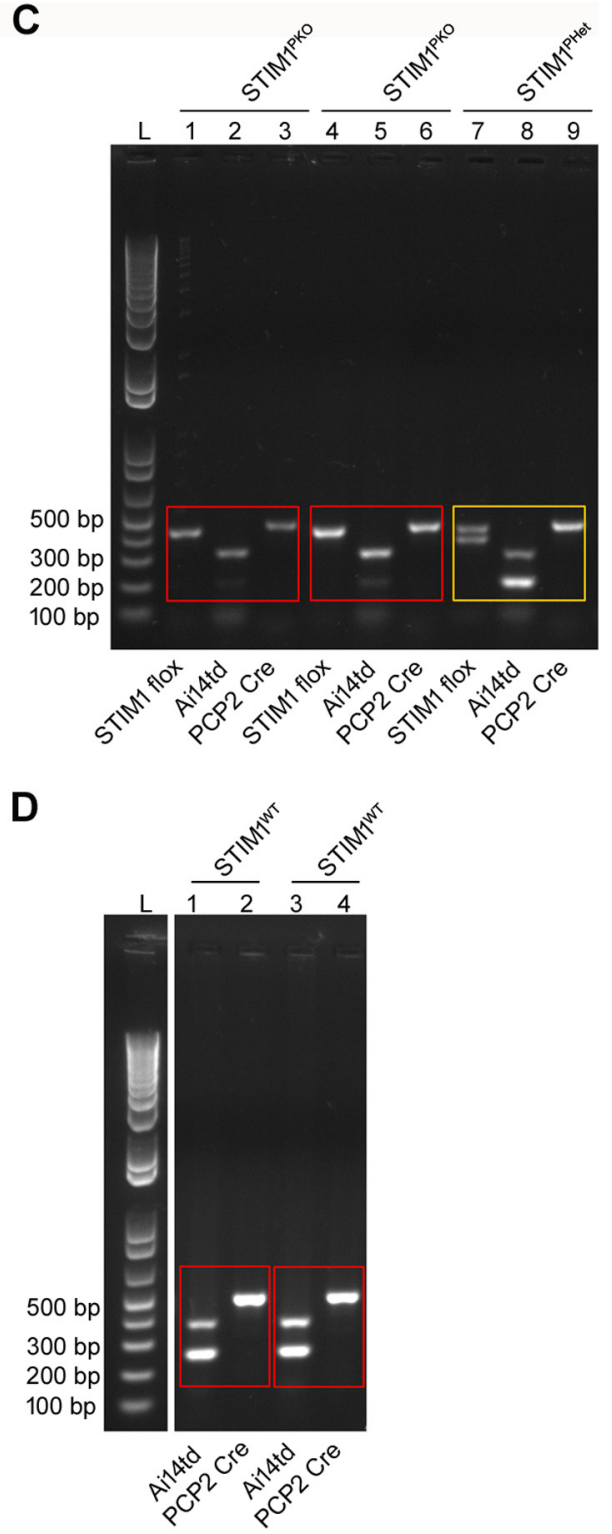

Figure 1. Genotyping of control and STIM1 KO transgenic mice. A, Top, Schematic diagram showing exon 2 of STIM1 gene flanked by loxP recombination sites (yellow triangles). Deletion of this exon following Cre-mediated recombination is expected to result in a frame shift that generates a premature stop codon in the next exon. Middle, Schematic diagram showing Cre reporter cassette inserted into the intron between endogenous exons 1 and 2 of the Rosa26 locus. Bottom, Schematic diagram showing insertion of Cre-recombinase CDNA into the exon 4 of $P C P 2$ gene. Primers are indicated by arrows (FP, forward primer; RP, reverse primer). $\boldsymbol{B}$, Top, Reporter mouse line with tdTomato-expressing Purkinje cells was generated by cross breeding floxed stop tdTomato mice (Ai14-tdTomato) and PCP2-Cre. Bottom, STIM1 PKO mouse line of tdTomato-expressing Purkinje cells was generated by cross breeding homozygous double transgenic

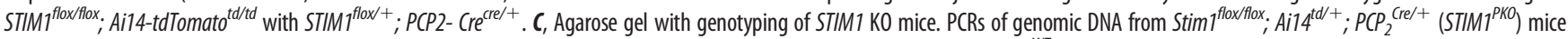
are given on lanes 1-3 and 4-6. A single band at 399 bp is for homozygous STIM1 flox (lanes 1, 4), two bands at 297 bp (Rosa ${ }^{W T}$ ) and 196 bp (Ai14tdT insert in the Rosa locus) (lanes 2, 5), and

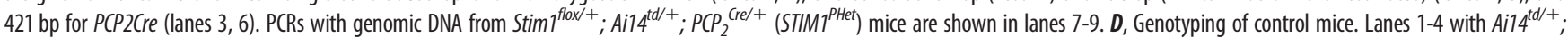
$P C P_{2}^{C r e /+}\left(S T I M 1^{W T}\right)$; sizes of DNA bands are as described above for $\boldsymbol{C}$. L, DNA ladder for both $\boldsymbol{C}$ and $\boldsymbol{D}$.

\section{Results}

\section{Characterization of STIM1 protein in cerebellar PNs across ages}

STIM1 is a key component of SOCE (Liou et al., 2005; Roos et al., 2005), and previous studies have shown that loss of STIM1 in PNs leads to changes in intracellular calcium homeostasis and reduced neuronal excitability. At the organismal level, loss of STIM1 in PNs affects motor learning and memory consolidation (Hartmann et al., 2014; Ryu et al., 2017). To understand the molecular basis of these deficits, we generated PN-specific STIM1 $\mathrm{KO}\left(S T I M 1^{P K O}\right)$ mice using the conditional Cre-lox system (see Materials and Methods). Exon 2, which encodes the EF hand of
STIM1 (Oh-Hora et al., 2008), was deleted using a PCP2 (L7)Cre transgenic mouse strain that exhibits near-specific expression in PNs postembryonic day 19 (Barski et al., 2000). To mark STIM1 KO neurons, a triple transgenic mouse strain was generated, where expression of the red fluorescent protein tdTomato was based on Cre activity (STIM1 $1^{\text {flox/flox }}$; Ai14Tdtomato ${ }^{\text {td/+ }}$; PCP2-Cre $e^{\text {cre/+ }}$, subsequently referred to as STIM1 ${ }^{\text {PKO }}$ ) (Fig. $1 A-$ $C)$. A double transgenic strain Ai14Tdtomato ${ }^{\text {td/+ }}$; PCP2-Cre cre/+ $^{\text {P }}$ $\left(S T I M 1^{W T}\right)$ was taken as the control (Fig. $\left.1 A, B, D\right)$.

It has been reported that Cre-mediated recombination by PCP2-Cre is fully established by postnatal day 21 (Barski et al., 2000). Therefore, we tested for loss of STIM1 from PNs at 6 

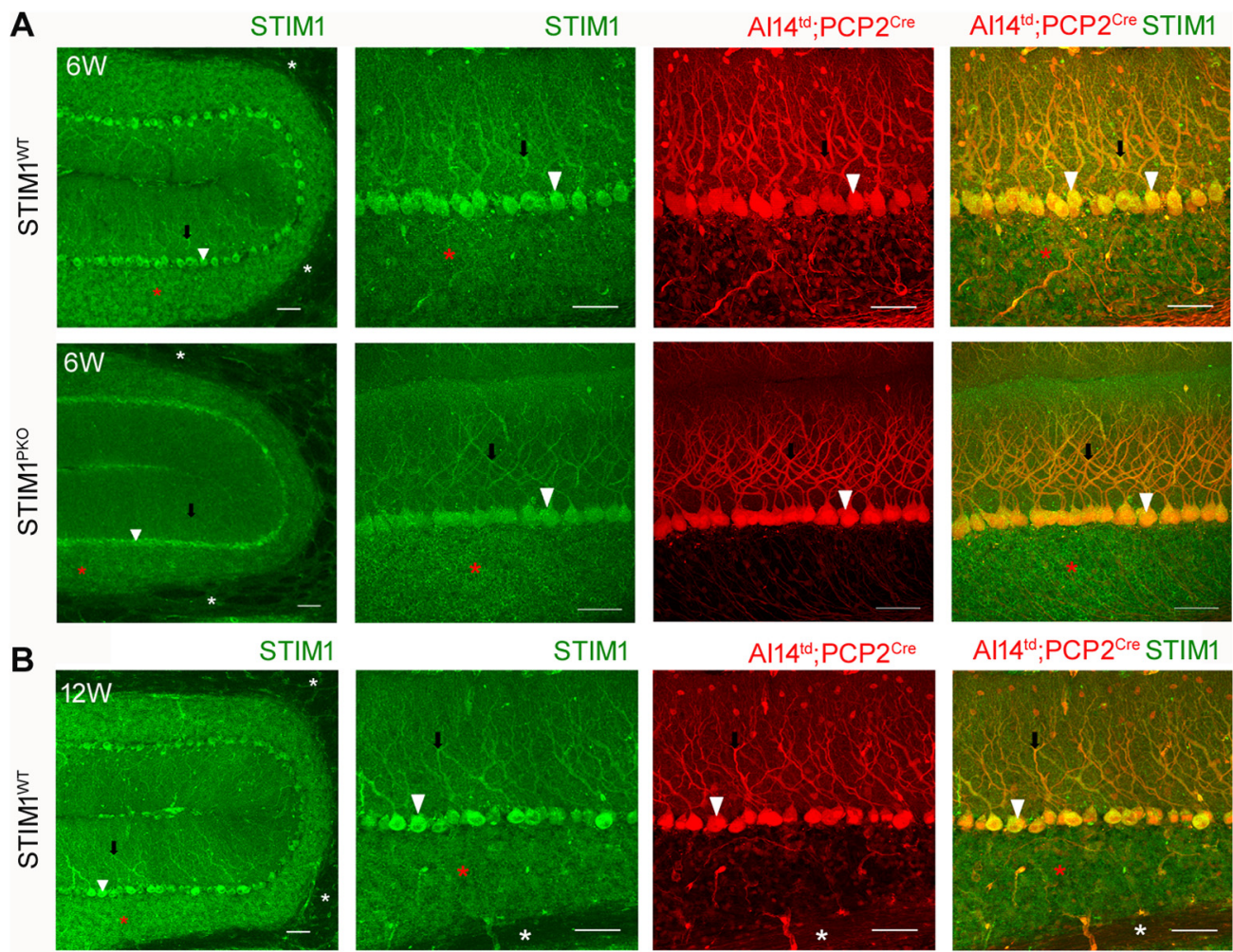

Al14 ${ }^{\text {td }} ;$ PCP2 ${ }^{\text {Cre }}$ STIM1
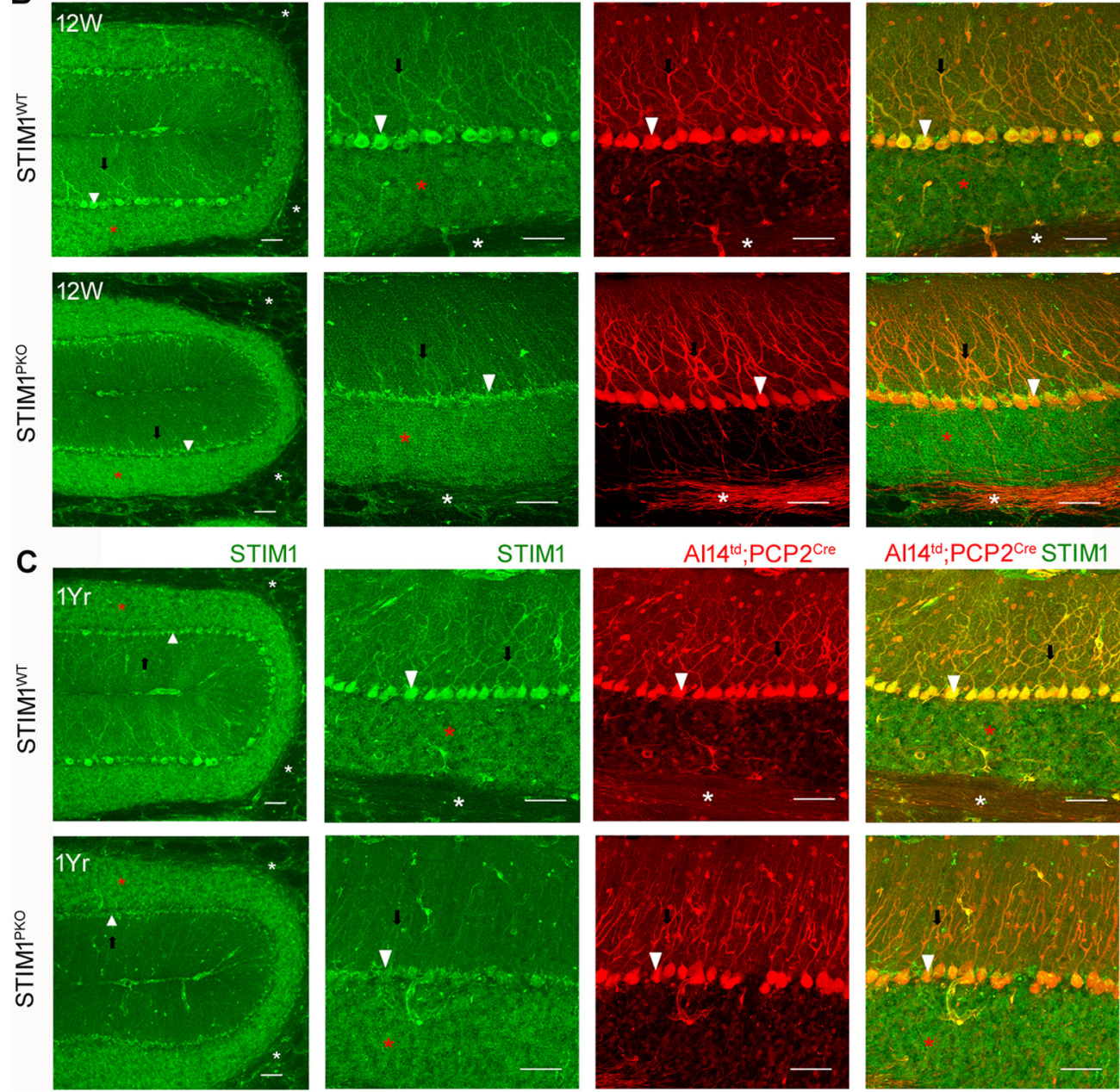

$\mathrm{Al}^{\mathrm{i}} 4^{\mathrm{td}} ; \mathrm{PCP} 2^{\mathrm{Cre}} \mathrm{STIM} 1$
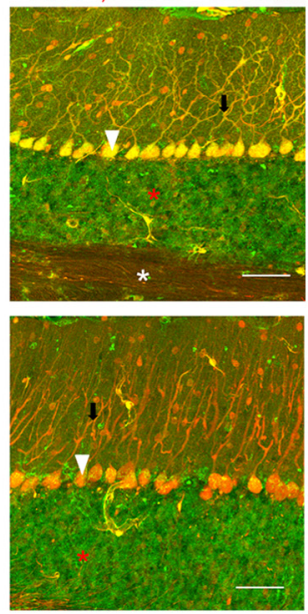

Figure 2. Loss of STIM1 occurs slowly after STIM1 KO in PNs. Cerebellar sections with PNs from STIM1 ${ }^{W T}$ and STIM1 ${ }^{P K O}$ mice, immunostained as indicated. Sagittal sections prepared from $S T I M 1^{W T}$ and STIM ${ }^{\text {PKO }}$ mice at 6 weeks $(\boldsymbol{A}), 12$ weeks $(\boldsymbol{B})$, and 1 year $(\boldsymbol{C})$ were stained with anti-STIM1 antibody and imaged at $20 \times$ (left) and $40 \times$. PNs (white arrows), GL (red asterisks), PN dendrites (black arrows), and PN axons (white asterisks) are marked. Scale bars, $50 \mu \mathrm{m}$. Quantification of STIM1 levels in the soma of PNs across different ages is shown in Figure 3.

weeks by immunohistochemistry. Despite expression of tdTomato in PNs at 6 weeks, indicating PCP2-Cre activity, a substantial level of STIM1 remained in the PNs (Fig. 2A, white arrowheads). Expression of STIM1 in the soma of PNs was not detected at 12 weeks, as evident by loss of colocalization between anti-STIM1 (green) and tdTomato (red; Fig. $2 B$, white arrowheads). In general, we observed that STIM1 expression was low in axonal processes
(Fig. 2, white asterisks) compared with PN soma and dendrites (Fig. 2, black arrows on PN dendrites). STIM1 expression in the granule layer (GL) of both control and STIM1 ${ }^{\text {PKO }}$ appears unaltered in the immunostained sections (GL, red asterisks). Quantification of STIM1 in PN soma, obtained by fluorescence intensity measurements, also identified residual STIM1 in STIM1 ${ }^{P K O}$ PNs from mice 6 weeks of age, that was significantly reduced by 12 weeks (Fig. $3 \mathrm{~A}$, 
A
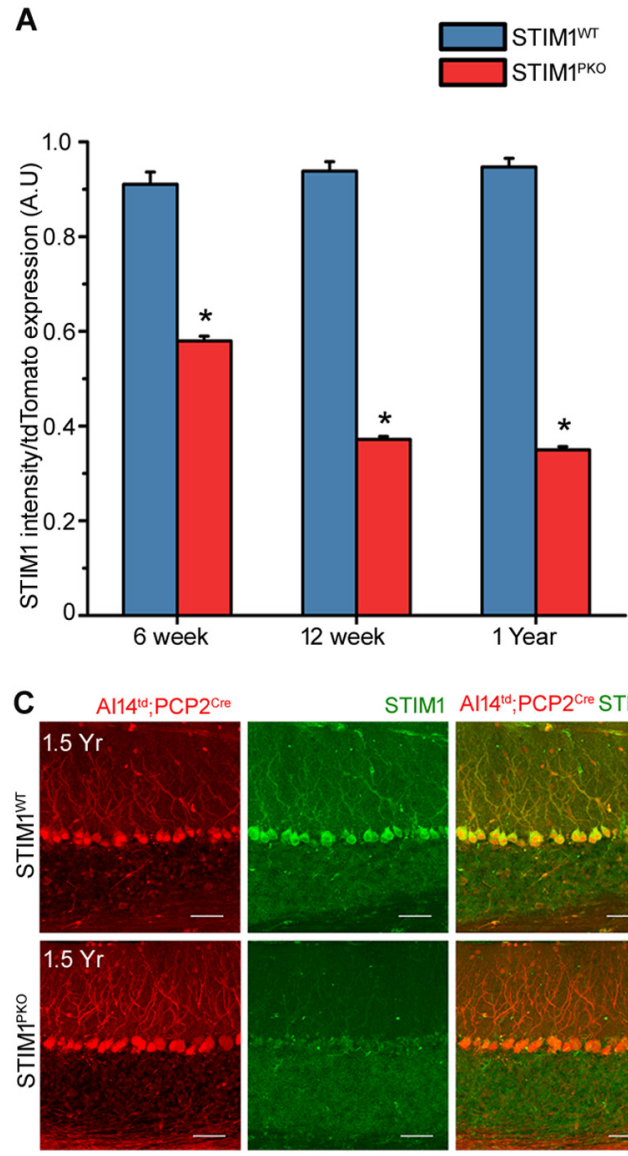

B
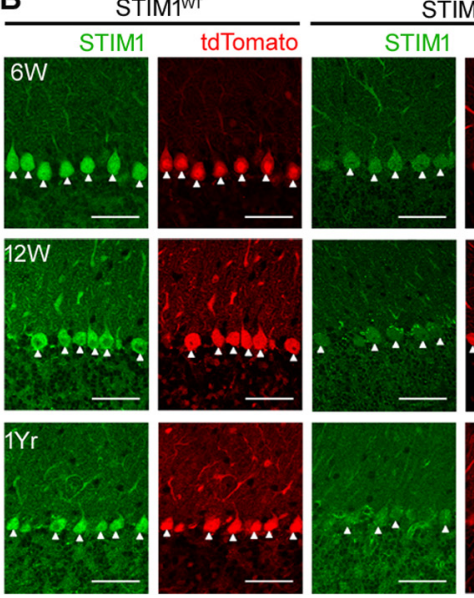

STIM1PKO

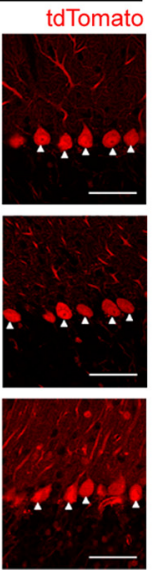

$\mathrm{S} 100 \mathrm{~B} \quad \mathrm{Al} 14^{\text {td }}: \mathrm{PCP} 2^{\mathrm{Cre}} \mathrm{S} 100 \mathrm{~B}$
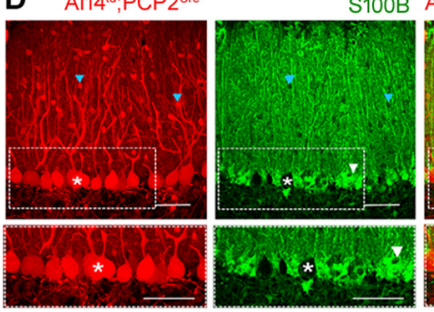

Figure 3. Quantification of STIM1 and characterization of PNs and Bergmann glia in cerebellar sections. A, Bar graph with quantification of STIM1 in the soma of PNs compared with the expression of tdTomato seen at 6 weeks (STIM1 ${ }^{W T}, n=53$ PNs; STIM1 ${ }^{\text {PKO }}, n=68$ PNs), 12 weeks (STIM1 ${ }^{W T}, n=64$ PNs; STIM1 ${ }^{\text {PKO }}, n=74$ PNs), and 1 year (STIM1 ${ }^{\text {WT }}$, $n=65$ PNs; STIMP $7^{P K O}, n=77$ PNs). Immunofluorescence intensities of STIM1 and tdTomato were quantified from PN soma by placing identical hand-drawn ROIs on the respective images, using ImageJ software. The total PNs analyzed are from 3 mice per group. Data are mean \pm SEM. ${ }^{*} p<0.001$ (two-tailed Student's $t$ test). $\boldsymbol{B}$, Representative images of confocal sections from the indicated genotypes and ages showing the STIM1 (green) and tdTomato (red) in PN soma (white arrowheads). C, Immunostained cerebellar sections from STIM $1^{W T}$ and STIM ${ }^{P K O}$ mice 1.5 years of age with intact PNs. Red represents tdTomato. Green represents STIM1. D, Characterization of Bergmann glia marked by S100B in cerebellar sections from control mice 1 year of age. Top, Sagittal sections were imaged at $40 \times$ magnification. Bottom, An enlarged image is shown with the location of the Bergmann glial cell body. A PN and a Bergmann glial cell body are marked with white asterisks and white arrowheads, respectively. Cyan arrowheads indicate non-Purkinje cells expressing tdTomato and not marked by S100B. Scale bars: $\boldsymbol{B}-\boldsymbol{D}, 50 \mu \mathrm{m}$.

$B)$. Loss of STIM1 did not affect the viability of PNs until 1 and 1.5 years, as evident in Figures $2 C$ and $3 C$. The time lag between Cre expression (3 weeks) and loss of STIM1 protein (12 weeks) might be because of slow protein turnover of STIM1. Alternately, there might be a difference between recombination efficiency of the STIM1 flox allele and the tdTomato flox allele. A few interneurons in the ML also express tdTomato indicating PCP2-Cre expression in cells other than PNs. Subsequent studies for understanding STIM1 function in PNs were performed in mice 12 weeks of age or older.

\section{Loss of STIM1 in PNs leads to deficits in motor learning and coordination}

Previous studies have reported the importance of STIM1 in regulating cerebellar motor behavior (Hartmann et al., 2014) and memory consolidation (Ryu et al., 2017). To identify the exact stage at which the motor learning phenotype develops and to investigate its progression with age, control and STIMI ${ }^{P K O}$ mice were subjected to a standard rotarod assay over $5 \mathrm{~d}$ (Hartmann et al., 2014) (see Materials and Methods). During each test session, animals were placed on a rotating rod that was accelerated continuously from 5 to $45 \mathrm{rpm}$, and the time at which the animal fell off the accelerating rotarod was noted. The ability to stay longer on the rotarod indicates better motor learning and coordination. Whereas both control and STIM1 ${ }^{P K O}$ mice performed comparably at either 9 or 14 weeks (Fig. $4 A, B$ ), a significant decrease in time spent by STIM1 ${ }^{P K O}$ mice on the accelerating rotarod was evident from 17 weeks onward, particularly after $4 \mathrm{~d}$ of training (Fig. 4C). Comparable rotarod performance at 9 and 14 weeks is not surprising given that STIM1 immunoreactivity from STIM1 ${ }^{P K O}$ PNs is lost at 12 weeks. In control mice, average latency to fall improved from $152.4 \pm 7.2 \mathrm{~s}$ (day 1) to $232 \pm 12.7$ s over $5 \mathrm{~d}$ (Fig. $4 \mathrm{C}$ ) in case of mice 17 weeks of age. In contrast, STIM1 ${ }^{\text {PKO }}$ mice fell off the rotarod with a similar latency as controls on day 1 (146.4 $\pm 10.1 \mathrm{~s})$ but over $5 \mathrm{~d}$ did not exhibit improvement to the same extent as controls (day 5, $163.1 \mathrm{~s}$; Fig. $4 C$ ). The same trend was observed at 29 weeks (Fig. $4 D$ ) and at 1 year of age (Fig. $4 E$ ). To our surprise, we also observed a decrease in the latency on the rotarod in case of STIMI ${ }^{\text {PHet }}$ animals compared with that of control mice at all ages tested, indicating an effect of the loss of one copy of STIM1 in PNs on motor learning. Progression of the deficit in motor learning with age appeared similar in control, STIM1 $1^{P H e t}$, and $S T I M 1^{P K O}$ mice, as evident by comparing motor performance across ages on the fifth day of training (Fig. 4F). 


\section{Reduced membrane depolarization and loss of mGluR1 stimulated $\mathrm{Ca}^{2+}$ signals in STIM1 KO PNs}

It is likely that altered calcium homeostasis in $S T I M 1^{P K O}$ PNs underlies the motor learning deficits observed in STIM1 ${ }^{P K O}$ mice. Because STIM1 is an integral component of SOCE in both nonexcitable (Liou et al., 2005; Roos et al., 2005; Oh-Hora et al., 2008; H. Cheng et al., 2016) and excitable cells (Venkiteswaran and Hasan, 2009; Gruszczynska-Biegala et al., 2011; Hartmann et al., 2014; Ryu et al., 2017), as a first step we investigated SOCE in cultured PNs obtained from postnatal day 1 mice and cultured for $14 \mathrm{~d}$ (Fig. 5). In comparison with control PNs (Ai14Tdtomato ${ }^{\text {td/+ }} ; \mathrm{PCP} 2-\mathrm{Cre}^{\mathrm{cre} /+}$ ), SOCE from STIM1 ${ }^{P K O}$ PNs was muted but not abolished (Fig. 5A,B). The continued presence of reduced levels of STIM1 protein even after gene $\mathrm{KO}$, as evident in Figures 2 and $3 A, B$, probably contributes to the SOCE in STIM $1^{\text {PKO }}$ PNs. Our efforts to culture PNs either beyond $14 \mathrm{~d}$ or from cerebella of mice older than postnatal day 7 were not successful, hindering attempts to measure SOCE from PNs in which the STIM1 protein was abolished. Instead, calcium transients were measured in acute cerebellar slices from PNs expressing the genetically encoded calcium sensor, GCaMP6f using twophoton calcium imaging (Fig. 6). Changes in excitability between control PNs and STIM1 $1^{\text {PKO }}$ PNs were measured from cerebellar slices of mice 17 weeks of age and stimulated with 75 $\mathrm{mm} \mathrm{KCl}$. WT PNs show robust cytosolic calcium elevations on addition of $\mathrm{KCl}$ (Fig. 6A-E, blue trace), whereas calcium responses from $S T I M 1^{P K O} \mathrm{PNs}$ were significantly reduced compared with that of controls (Fig. 6A-E, red trace). The significant reduction in calcium responses of STIM1 ${ }^{P K O} \mathrm{PNs}$, on depolarization with $\mathrm{KCl}$, agrees with the motor deficit observed in mice 17 weeks of age (Fig. 4C). These data are also in agreement with a range of electrophysiological measurements, including current clamps undertaken in-depth in a previous study (Ryu et al., 2017). The authors found reduced firing frequency and reduced excitability in STIM1 ${ }^{P K O}$ PNs, which they attribute to the dysregulation of ionic currents through multiple membrane channels by changes in intracellular calcium dynamics (Ryu et al., 2017).

The mGluR1 is abundantly expressed in PNs (Lein et al., 2007; Ohtani et al., 2014). Mice with genomic deletion of $m$ GluR1 exhibit severe ataxic symptoms (Aiba et al., 1994) that can be rescued by expression of mGluR1 exclusively in PNs (Ichise et al., 2000). Moreover, autoantibodies against mGluR1 in humans with paraneoplastic cerebellar ataxia (Smitt et al., 2000; Coesmans et al., 2003) impair cerebellar motor coordination. Thus, mGluR1 signaling in PNs is required for cerebellar function, including motor learning and coordination. We assessed mGluR1 activation in the PNs of both control and STIM1PKO mice by stimulating cerebellar slices with the mGluR1 agonist DHPG $(200 \mu \mathrm{M}$, Fig. $6 F-H)$. In control PNs, DHPG stimulation evoked large calcium transients in most PNs (Fig. 6F,H),
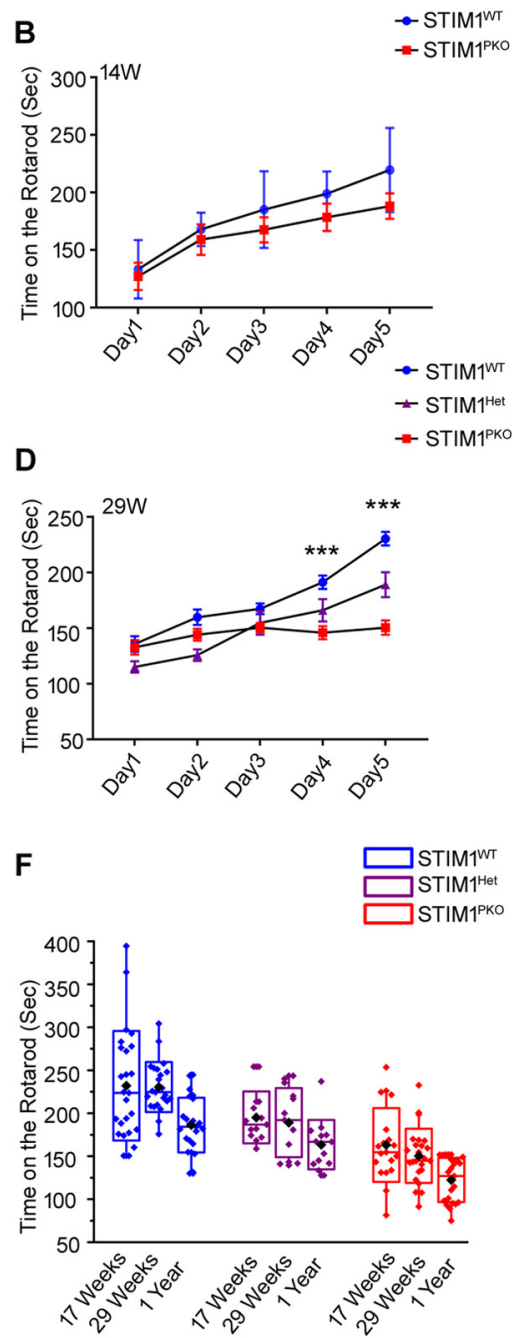

Figure 4. Motor coordination deficits in STIM1 KO mice. A, Mean latency on the rotarod for STIM $1^{W T}$ and STIM1 $1^{\text {PKO }}$ mice at 9 weeks $\left(S T I M 1^{W T}\right.$ and STIM1 $\left.{ }^{\text {PKO }} ; n=5\right)$ and $(\boldsymbol{B})$ at 14 weeks $\left(S T I M 1^{W T}, n=7\right.$ and STIM1 $\left.{ }^{\text {PKO }}, n=5\right)$. Two-way ANOVA, post hoc test, and Sidak's multiple comparison test were used for comparisons. $\boldsymbol{C}-\boldsymbol{E}$, Mean latency on the estimated using two-way ANOVA, post hoc test, followed by Tukey's multiple comparisons test. ${ }^{*} p<0.05$; ${ }^{* *} p<0.001$; ${ }^{* *} p<0.0001$; comparison of STIM1 ${ }^{W T}$ and STIM1 ${ }^{\text {PKO }}$ mice. $\boldsymbol{F}$, Latencies to fall from the accelerated indicates the median. Black solid diamond represents the mean. Colored diamonds represent individual data points. In every box plot, the limits extend from 25 th to 75 th percentile.

although initiation of the calcium responses by DHPG occurred at varying time points in different PNs (Fig. $6 F$ ). This variation in the response time could be because of differences in the time taken for DHPG to reach the area focused under the microscope. Interestingly, in STIM1 ${ }^{P K O} \mathrm{PNs}$, DHPG application failed to evoke measurable calcium transients (Fig. $6 G, H$ ). The specificity of mGluR1 activation was tested by addition of CPCCOEt, an mGluR1 antagonist (Hartmann et al., 2008). Application of CPCCOEt $(200 \mu \mathrm{M})$ abolished the DHPG-induced calcium responses otherwise observed in control PNs (Fig. 6I). Notably, loss of mGluR1 activation observed in STIM1 ${ }^{P K O}$ PNs from mice 17 weeks of age (Fig. $6 G, H$ ) occurs within a few weeks of loss of STIM1 protein (12 weeks, Fig. $2 B$ ) and also correlates with the onset of motor dysfunction noticed in $S T I M 1^{\text {PKO }}$ mice (17 weeks, Fig. 4C). These data demonstrate that STIM1 is required for a significant proportion of mGluR1-activated calcium transients that appear in the soma and dendrites of PNs. A previous study demonstrated significant reduction in DHPG-evoked 
inward currents and local $\mathrm{Ca}^{2+}$ transients in the dendrites of $S T I M 1^{P K O} \mathrm{PNs}$, which they attribute to reduced levels of $\mathrm{Ca}^{2+}$ in dendritic ER stores that in turn are insufficient to stimulate DHPG-evoked slow EPSC $\mathrm{Ca}^{2+}$ currents (sEPSCs) (Hartmann et al., 2014). Because DHPG-evoked ER-Ca ${ }^{2+}$ release followed by $\mathrm{Ca}^{2+}$ entry resulting from the overlap in time of sEPSCs (Hartmann et al., 2014), these cannot be easily distinguished from each other, but it is likely that the larger amplitude and longer time scale of the sEPSCs contribute primarily to the $\mathrm{Ca}^{2+}$ signals seen in Figure $6 F$. Thus, our findings further augment the role of STIM1 in regulating neuronal excitability and synaptic transmission.

KO of STIM1 alters the profile of gene expression in PNs

A key aim of this study was to understand long-term molecular and cellular changes that occur in fully differentiated PNs because of dysregulated intracellular calcium signaling and SOCE by loss of STIM1. Changes in gene expression have been reported on reduced SOCE in nonexcitable immune cells (Feske, 2007), the developing mouse brain (Somasundaram et al., 2014), Drosophila pupal neurons (Richhariya et al., 2017), and human neural precursor cells (Gopurappilly et al., 2018). Gene expression profiles of mature differentiated neurons with loss of STIM1/nSOC have not been published to date. To test for gene expression changes in STIM1 ${ }^{P K O}$ PNs, we micro-dissected PNs from 1-year-old STIM1 $1^{P K O}$ and control animals. RNA was isolated from the PNL+ML (Fig. 7A) and from the GL. Specificity of tissue dissection was tested by measuring levels of RNA of a Purkinje neuronal marker, the Purkinje cell protein-2 (PCP2), and a granule cell marker, the GABA(A) receptor $\alpha 6$ subunit (GABRA6) (Boyden et al., 2006). Micro-dissected PNL and ML from control and STIM ${ }^{P K O}$ cerebella showed high expression of PCP2 compared with the granular layer (Fig. 7B, left) and a low level of the granule cell marker GABRA6 (Fig. 7B, right), suggesting minimal contamination from granule neurons in the PN-ML sample. Importantly, a significant reduction of STIM1 RNA was observed in PN-ML isolated from the STIM1 KO mice compared with control mice (Fig. $7 B$, middle). STIM1 expression levels in the GL were not significantly altered (Fig. $7 B$, middle) as observed in the immunostained sections in Figure 2. Western blot data also showed that the STIM1 protein was significantly reduced in STIM1 ${ }^{\text {PKO }} \mathrm{PN}$-ML (Fig. 7C).

RNA expression studies were performed with RNA isolated from the PN-ML of STIM1 ${ }^{P K O}$ and control animals. Analysis of the RNA sequencing data demonstrated significant changes in gene expression in micro-dissected PN-ML from STIM1 ${ }^{P K O}$ cerebella compared with controls. Differentially expressed genes are shown as a volcano plot where red dots and green dots represent sets of transcripts expressed at significantly lower and higher levels in STIM1 ${ }^{P K O}$ PN-ML, respectively (Fig. 7D; EdgeR analysis). The expression of 285 genes was significantly different between control and STIM1 ${ }^{P K O}$ PN-ML based on differential analysis by both EdgeR and DeSeq and $p<0.05$. Of these, 168 genes were downregulated and 117 were upregulated (Fig. 7E).

Interestingly, calcium signaling genes, such as $I P_{3} R 1, I P_{3} R 2$, and Orai3, and genes encoding calcium-binding proteins, such as parvalbumin (Pvalb), calmodulin1 (Calm1), calsequestrin 2 (Casq2), and S100B (S100 $\beta$ ), were significantly downregulated in STIM1 ${ }^{P K O}$ PN-ML (Fig. $7 F$ ). Expression of Orail appears very low in PNs of both STIM $1^{W T}$ (biological replicate read counts: 0 , 0,3 ) and STIM1 ${ }^{\text {PKO }}$ (biological replicate read counts: $0,2,0$ ) mice. Expression of Orai2 is slightly higher than Orail in both genotypes (STIM1 ${ }^{W T}$ biological replicate read counts: 7,11 , and
A
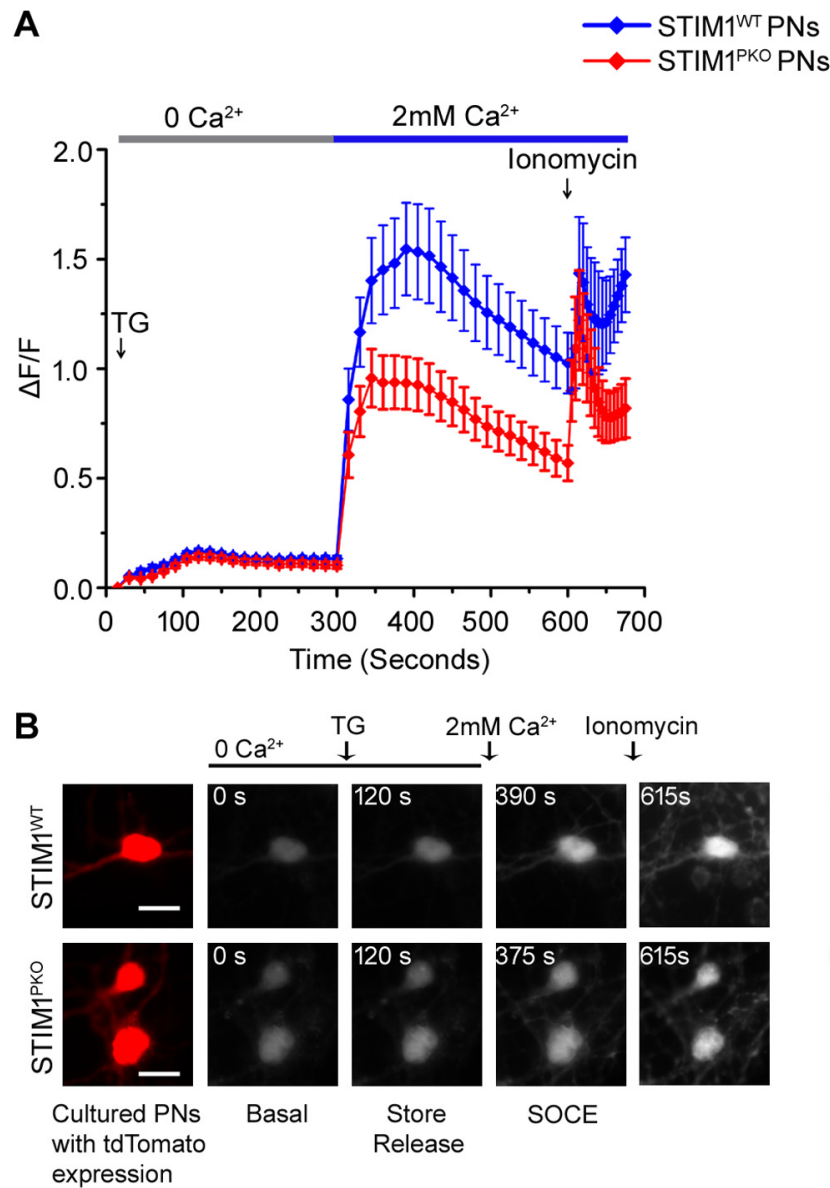

Figure 5. SOCE in cultured PNs. $\boldsymbol{A}$, Changes in cytosolic $\mathrm{Ca}^{2+}$ on ER store depletion by treatment with thapsigargin (TG) followed by SOCE on addition of extracellular $\mathrm{Ca}^{2+}$. PNs were obtained from P1 mice, cultured $14 \mathrm{DIV}$, and loaded with the $\mathrm{Ca}^{2+}$-sensitive dye, Fluo4 AM. Each trace represents the mean response curve of 31 PNs $\left(\right.$ STIM $7^{W T}$ ) and 14 PNs $\left(S T I M 7^{P K O}\right) . B$, Representative images of cultured PNs from the indicated genotypes showing tdTomato fluorescence, basal cytosolic $\mathrm{Ca}^{2+}\left(0 \mathrm{Ca}^{2+}\right)$ followed by changes in cytosolic $\mathrm{Ca}^{2+}$ levels on ER- $\mathrm{Ca}^{2+}$ store release (TG), SOCE $\left(2 \mathrm{~mm} \mathrm{Ca}{ }^{2+}\right)$, and measurement of dye saturation (ionomycin). Scale bars, $20 \mu \mathrm{m}$.

12 and STIM1 ${ }^{\text {PKO }}$ biological replicate read counts: 11,8 , and 7; from data in GEO: GSE158513). Neither Orai1 nor Orai2 expression appears affected in $\mathrm{PN}+\mathrm{ML}$ from $S T I M 1^{P K O}$ mice. Change in $S 100 \beta$ levels were intriguing because this protein is expressed in Bergmann glial cells (Fig. 3D, marked with white arrowheads) that are unipolar astrocytes located around PNs (Fig. 3D, marked with white asterisks) and Bergmann fibers enwrap synapses on Purkinje cell dendrites (Landry et al., 1989; Yamada and Watanabe, 2002; Hachem et al., 2007). Altered expression of S100 $\beta$ in STIM1 ${ }^{\text {PKO }}$ suggests that loss of mGluR1 signals and reduced excitability in PNs also affect gene expression of closely associated glial cells (see Discussion).

Abolishing STIM1 protein in PNs also reduced the expression of various ion channels and pumps, such as calcium voltagegated channel auxiliary subunit $\gamma 5$ (Cacng5), ATPase $\mathrm{Na}^{+} / \mathrm{K}^{+}$ transporting subunit $\alpha 3$ (Atp1a3), and synaptic signaling genes, such as Synaptotagmin 11 (Syt11) and vesicle-associated membrane protein 1 (Vamp1) (Fig. $7 F$ ). Thus, loss of STIM1 affects the expression of key components of intracellular $\mathrm{Ca}^{2+}$ signaling and homeostasis as well as some components of membrane excitability. Genes involved in regulation of cell cycle process, such as Plk4 (Polo-like kinase 4), Ovol1 (Ovo-like transcriptional 

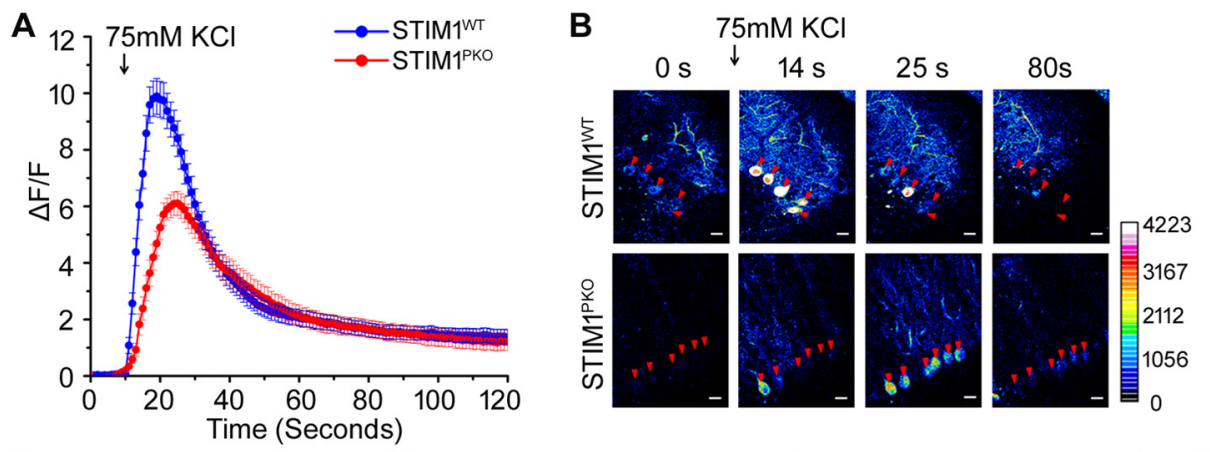

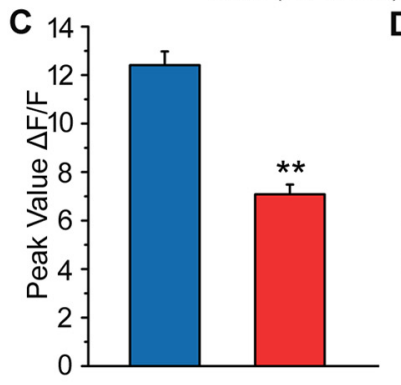

$\mathbf{F}$

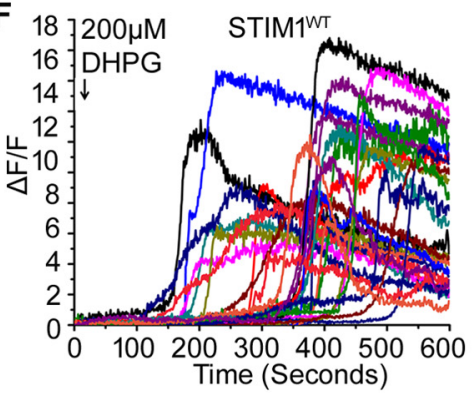

H
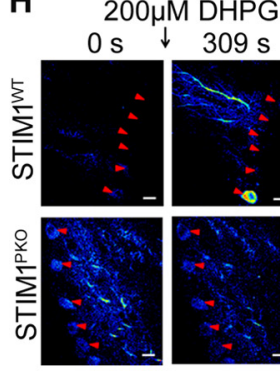

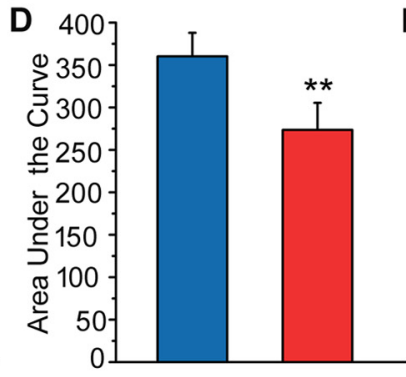

G
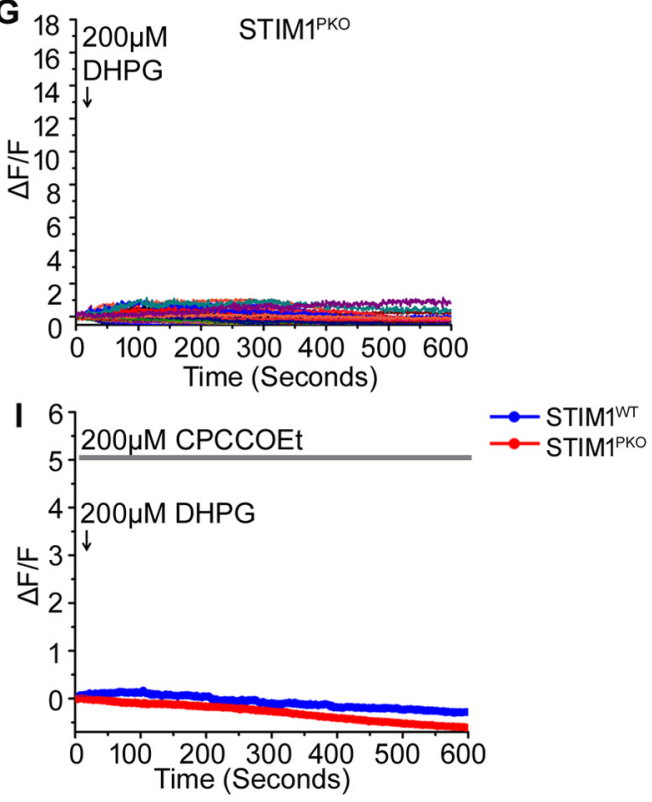

Figure 6. Reduced membrane depolarization and mGluR1 activation in STIM1 KO PNs. $A$, Line plot of the mean traces ( $\pm \mathrm{SEM})$ of normalized GCaMP6f fluorescence responses $(\Delta \mathrm{F} / \mathrm{F})$ in PN soma on $75 \mathrm{~mm} \mathrm{KCl}$ stimulation (STIM1 ${ }^{\mathrm{WT}}, 84 \mathrm{PNs}, 8$ mice; STIMP ${ }^{\mathrm{PKO}}, 44 \mathrm{PNs}, 5$ mice). $\boldsymbol{B}$, Representative images of changes in GCaMP6f fluorescence from PN soma at indicated time points following KCl stimulation. Red arrowheads indicate PN soma. Scale bars, $20 \mu \mathrm{m}$. C-E, Bar graphs with peak $\Delta \mathrm{F} / \mathrm{F}\left(S T M M 7^{W T}, 12.41 \pm 0.57 ;\right.$ STIM $\left.^{P K O}, 7.08 \pm 0.40 ; p=4.10 \times 10^{-12}\right)$, area under the curve $\left(S T I M 1^{W T}, 360.21 \pm 27.82 ; S_{T M} P^{P K O}, 273.59 \pm 31.92, p=0.04338\right)$, and rate of calcium entry $\Delta F / S e c\left(S T I M 1^{W T}, 2.54 \pm 0.27 ; S_{T M} P^{P K O}, 0.56 \pm 0.04, p=2.11 \times 10^{-10}\right)$ quantified from $\boldsymbol{A}$, respectively. Each bar is compared with control shown in blue. ${ }^{*} p<0.05$; ${ }^{* *} p<0.0001$; two-tailed Student's $t$ test. Line plots of GCaMP6f fluorescence responses ( $\left.\Delta \mathrm{F} / \mathrm{F}\right)$ in PN soma of $(\boldsymbol{F})$ control (30 PNs, 4 mice) and (G) STIM7 ${ }^{P K O}$ (55 PNs, 4 mice) on addition of the mGluR1 agonist, $200 \mu \mathrm{m}$ DHPG. $\boldsymbol{H}$, Snapshots of GCaMP6f responses from PN soma at indicated time points on DHPG stimulation. Red arrowheads indicate the PN soma. Scale bars, $20 \mu \mathrm{m}$. I, Mean traces ( \pm SEM) of normalized GCaMP6f fluorescence responses $(\Delta \mathrm{F} / \mathrm{F})$ in PN soma on DHPG stimulation in slices incubated with $200 \mu \mathrm{M}$ (PCCOEt, an mGluR1 antagonist (STIM1 ${ }^{\text {WT }}, 39$ PNs, 4 mice; STIM1 ${ }^{\text {PKO }}, 43$ PNs, 4 mice).

repressor 1), and Map6d1 (MAP6 domain containing 1), and those involved in regulation of cellular carbohydrate metabolic process, such as Bad (BclII Associated Agonist of Cell Death), Insr (Insulin Receptor), and Kat2b (Lysine Acetyltransferase 2B), are significantly upregulated (Fig. $7 G$ ). Together, these data suggest that signaling through STIM1 has an important role in regulating gene expression in mature differentiated PNs.

Biological pathways affected by absence of STIM1 in PNs To further understand the nature of signaling mechanisms regulated by STIM1 in murine PNs, we used Metascape to predict the
GO of differentially regulated genes (Figs. 8, 9). Endocytic recycling, neuron projection development, protein transport, ER calcium ion homeostasis, postsynapse organization, and glutamate receptor signaling pathway were among significantly downregulated GO biological processes (Fig. 8A). A network plot of GO biological processes for the downregulated gene set was constructed using Metascape (Fig. $8 B$ ) to help understand intercluster gene similarities and intracluster gene redundancies among the enriched GO terms. Regulation of neuron projection development (blue) and postsynapse organization (gray) share several genes, and the interconnecting edges indicate the relative 
A

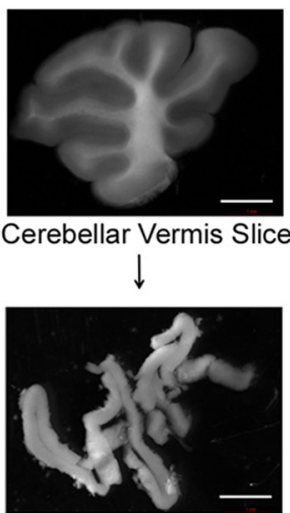

Purkinje Layer + Molecular Layer

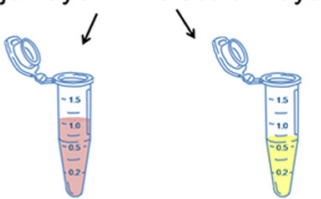

RNA extraction Protein Isolation RNA seq Western Blot
B

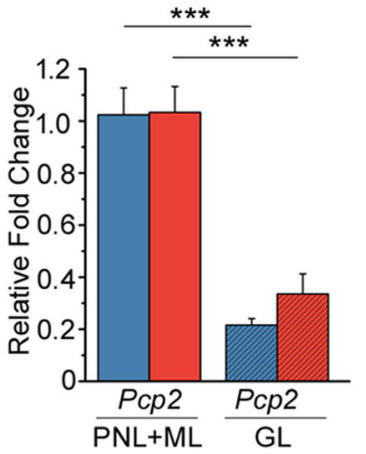

C

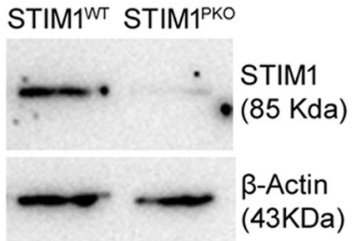

E

Deseq

EdgeR
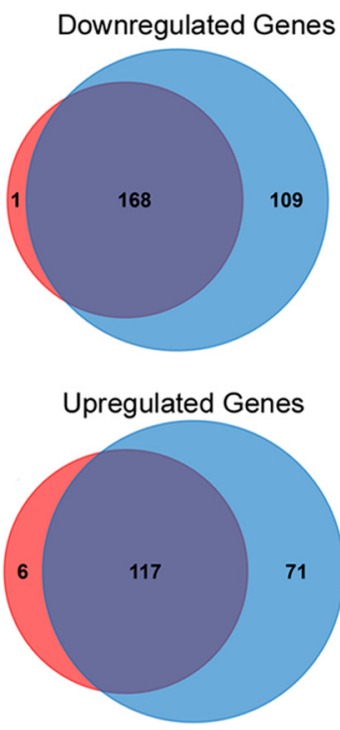

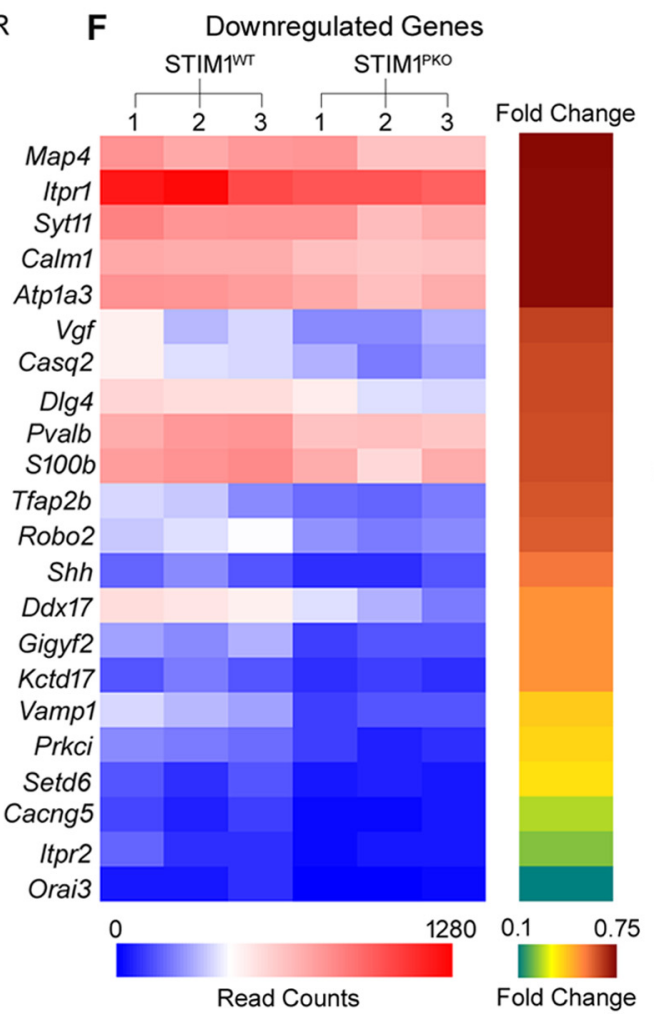

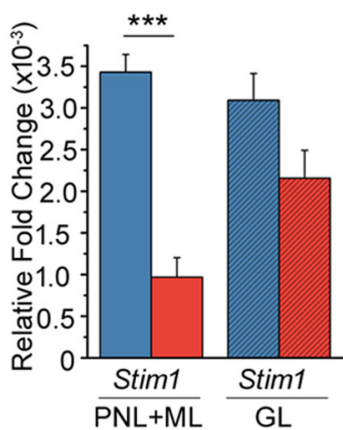

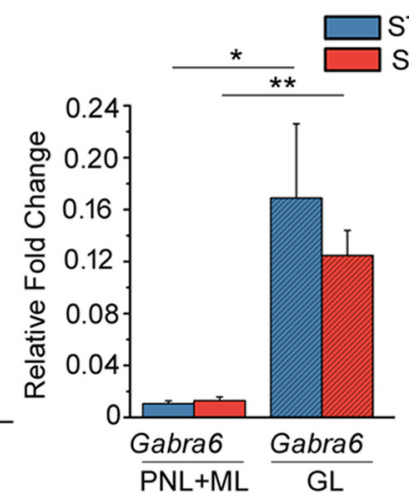

D

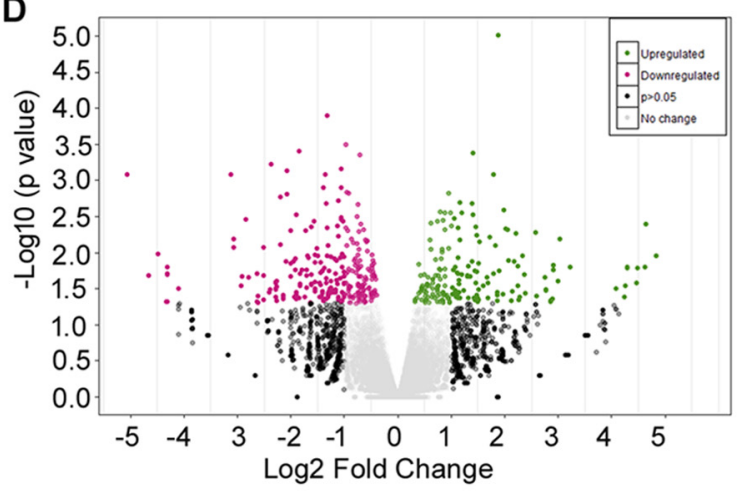

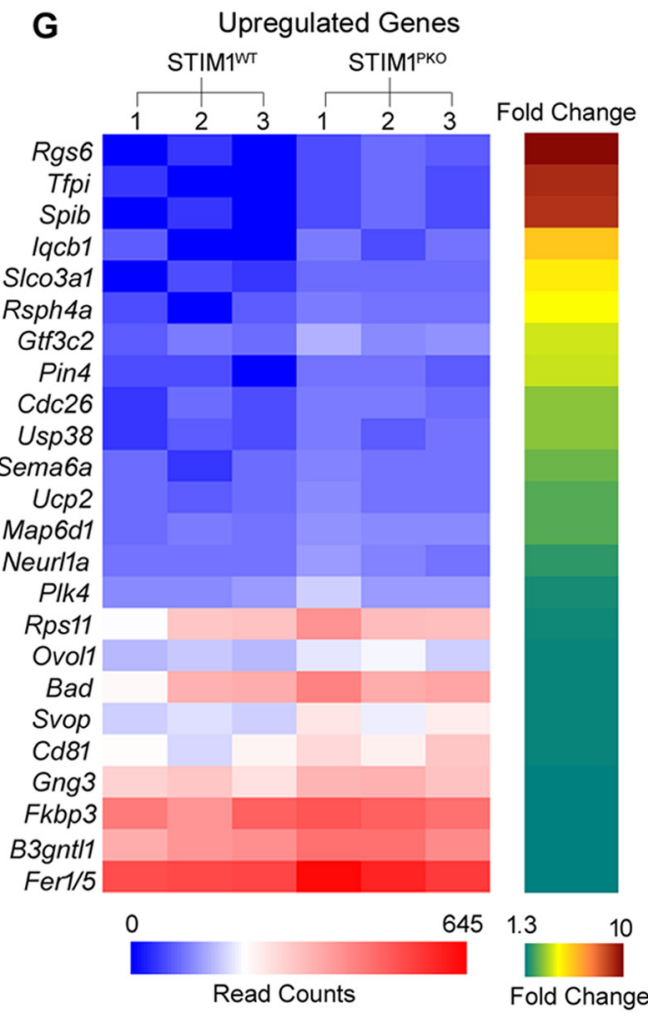

Figure 7. RNA Seq reveals gene expression changes in PNs from STIM7 ${ }^{P K O}$ mice. $A$, Images of a micro-dissected PNL $+M L$ and a schematic representation for extracting RNA and protein. Scale bar, $1 \mathrm{~mm}$. B, Bar graphs represent comparative expression levels of a PN marker, PCP2 (Purkinje cell protein 2), STIM1 (Stromal Interaction Molecule 1), and a GL marker GABRA6 (GABA type A receptor subunit alpha6) normalized to GAPDH (glyceraldehyde 3-phosphate dehydrogenase) in samples of PNL+ML and GL. RNA expression was measured by qRT-PCR from the microdissected samples. Fold changes of STIM1 and GABRA6 are relative to the expression levels of Control PCP2 ( $n=6$ mice, 1 year). Relative fold change of $P C P 2$ in STIM1 ${ }^{W T}$ (PNL $\left.+M L\right)$,

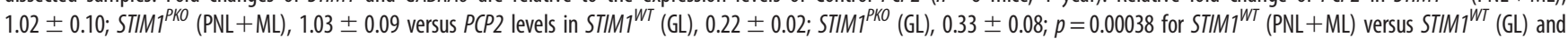
$p=0.00031$ for STIMT ${ }^{P K O}$ (PNL+ML) versus STIM7 $7^{P K O}$ (GL). Relative fold change of STIM1 in STIM1 ${ }^{W T}$ (PNL + ML), $3.43 \pm 0.21 \times 10^{-3} ;$ STIM $^{P K O}(\mathrm{PNL}+\mathrm{ML}), 0.969 \pm 0.23 \times 10^{-3} ; p=1.5-$ $\times 10^{-5}$. Relative fold change of GABRA6 in STIM7 ${ }^{W T}$ (PNL + ML), $0.01 \pm 0.002$ versus STIM1 ${ }^{W T}$ (GL), $0.17 \pm 0.06, p=0.03931$ and STIM7 $7^{\text {PKO }}$ (PNL + ML), $0.01 \pm 0.003$ versus STIM7 ${ }^{\text {PKO }}$ (GL), $0.12 \pm 0.02, p=0.00195$. Data are mean \pm SEM. ${ }^{*} p<0.05 ;{ }^{* *} p<0.01 ;{ }^{* * *} p<0.001$; two-tailed Student's $t$ test. C, Western blot showing STIM1 levels in control and STIM1 K0 micro-dis-

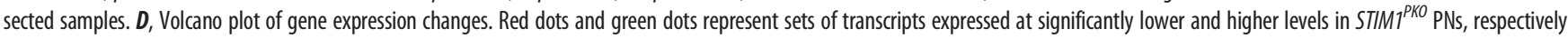


relatedness of these two processes. As might be expected, endocytic recycling (red), receptor-mediated endocytosis (green), lysosomal transport (pink), and membrane organization (light blue) form a tight network. Interestingly, genes in the ER calcium ion homeostasis cluster (brown) form a distinct cluster that is interlinked through the glutamate receptor-signaling pathway (light blue) with postsynapse organization and receptor-mediated endocytosis (Fig. 8B; Extended Data Fig. 8-1). This analysis suggests that loss of STIM1-mediated $\mathrm{Ca}^{2+}$ signaling in PNs further affects the expression of genes that influence ER calcium ion homeostasis, glutamate receptor signaling, neuron excitability, and synaptic transmission.

Biological pathways associated with regulation of cell cycle process, meiotic cell cycle, signal release, cell development, cellular carbohydrate metabolic process, and transmembrane transport are significantly upregulated in the STIM1 ${ }^{\text {PKO }}$ PNs (Fig. $8 C$ ). Clustering of upregulated genes from "GO biological process" shows that regulation of cell cycle processes is the most enriched pathway with gene sets being shared among its various subclusters; no intercluster connections with other GO terms were observed (Fig. 8D; Extended Data Fig. 8-2).

A similar GO analysis of cellular components identified three interrelated clusters of "neuron to neuron synapse," "axon," and "presynapse" among the downregulated genes in STIM1 ${ }^{\text {PKO }}$, supporting an effect of STIM1-mediated $\mathrm{Ca}^{2+}$ signaling on multiple synaptic components, including postsynaptic densities, synaptic membranes, and glutamatergic synapses (Fig. 9A,B; Extended Data Fig. 9-1). A second set of interrelated clusters, "early endosome," "cytoplasmic vesicle part," and "membrane coat," suggest an effect on vesicular transport. Interestingly, the KEGG pathway and Reactome analysis identified an interconnected network that links to Alzheimer's disease and includes several nodes belonging to ion homeostasis (Fig. 9C,D; Extended Data Fig. 9-2). The functional relevance of single nodes in the network plots is hard to assess from this analysis. Together, these findings indicate that regulation of gene expression by STIM1 impacts various biological, cellular, and molecular processes that could in turn alter synaptic morphology and function as well as neuronal excitability.

\section{Gene expression changes because of loss of STIM1 are age- dependent}

Next, we investigated the age at which gene expression changes occur after STIM1 KO in PNs. Accordingly, candidate genes from various GO-enriched categories (Fig. 8) were chosen, including calcium signaling, voltage-gated ion channels, synaptic signaling, neuron projection development, transcription factors, and carbohydrate metabolic process, and their expression was measured by qRT-PCR in RNA isolated from the dissected cerebella of control and STIM1 ${ }^{P K O}$ mice at 14 weeks and 1 year. Interestingly, expression level of genes encoding $\mathrm{IP}_{3} \mathrm{R} 1$, Orai3, and calcium-binding proteins, such as Pvalb, Calm1, Casq2, and S100B, were significantly downregulated at 1 year (Fig. $10 \mathrm{~A}$, red vs blue bars) but not at 14 weeks of age (Fig. 10A, dark pink vs light purple bars). A similar pattern of age-dependent changes in

\footnotetext{
(EdgeR analysis). RNA-Seq experiments were performed with three biological replicates from 1 -year-old mice. $\boldsymbol{E}$, Venn diagrams representing the number of genes identified as differentially expressed by DEseq and EdgeR analysis. $\boldsymbol{F}, \boldsymbol{G}$, Heat maps depicting read counts of selected downregulated $(\boldsymbol{F})$ and upregulated $(\boldsymbol{G})$ genes, in order of maximal average fold change (right panels), from WT and STIM1 KO conditions, are shown for three biological replicates (left panels).
}

gene expression was observed for all other gene classes tested by qRT-PCR (Fig. 10B-F). Results of the qRT-PCR experiments from STIM $1^{P K O}$ animals 1 year of age helped to validate the change in gene expression of various ion channels and pumps, such as Cacng5, Atp1a3, and Kctd17 (Fig. 10B), and synaptic signaling genes, such as Syt11 and Vamp1 (Fig. 10C). In addition, we confirmed the downregulation of genes involved in neuron projection development, such as Dlg4 (discs large homolog 4), Robo2 (Roundabout guidance receptor 2), Gigyf2 (GRB10 Interacting GYF Protein 2), and Map4 (Microtubule-associated protein 4) (Fig. 10D) and those involved in regulating gene expression, such as Tfap $2 b$ (Transcription factor AP-2 $\beta$ ) and Setd6 (SET domain containing 6) (Fig. 10E) in STIM1 ${ }^{P K O}$ PNs. Two upregulated genes, Bad and Insr, both related to carbohydrate metabolic process, were also validated (Fig. 10F).

Possibly the altered gene expression observed in 1-year-old STIM1 ${ }^{P K O}$ PNs arises from a combinatorial effect of loss of mGluR1 signals through STIM1 (Fig. 6G,H), and other mechanisms that are dysregulated because of prolonged loss of STIM1dependent signaling in PNs, such as reduced excitability (Fig. $6 A-E)$. Alternatively, in the initial phase of STIM1 KO, certain compensatory mechanisms might exist that are abrogated with age. These findings suggest that changes in neuronal activity (Fig. 6) and onset of motor dysfunction (Fig. 4), because of loss of STIM1 in PNs, precede changes in gene expression (Figs. 7-10).

\section{Dendritic morphology of PNs undergoes subtle changes in STIM1 KO animals}

PNs integrate afferent inputs received on an elaborate dendritic tree and their function is largely influenced by development and maintenance of dendritic morphology and spine density (K. J. Lee et al., 2005; McKay and Turner, 2005). Based on our findings that genes for neuron projection development, such as Dlg4, Robo2, Gigyf2, and Map4 (Figs. 8, 10), were significantly downregulated in PNs of STIM1 $1^{P K O}$ mice, and that changes in the dendritic pattern might also occur because of altered regulation of genes for aspects of metabolic regulation (Figs. 8, 9) (Bauernfeind et al., 2014; Steiner, 2019; Maffezzini et al., 2020); we investigated the dendritic morphology of PNs. Dendritic arborization of the primary and secondary dendritic branches of PNs were traced using the Filament Tracer (Auto Depth) tool of Imaris software (Fig. $11 A$; see Materials and Methods). The number of intersections observed at specific distances from the soma were quantified to obtain a measure of the dendritic branch complexity (Fig. 11B). A significant reduction in the number of intersections was observed at a distance of $120-140 \mu \mathrm{m}$ from the Purkinje soma $(p<0.0001$ at $120 \mu \mathrm{m}, p<0.05$ at $130 \mu \mathrm{m}$, and $p<0.01$ at $140 \mu \mathrm{m}$, two-way ANOVA, Sidak's multiple comparisons test; Fig. $11 B$ ) as indicated in Figure $11 A$ (white arrowheads, at $120 \mu \mathrm{m}$ ), suggesting reduced inputs from parallel fibers (Ichikawa et al., 2002, 2016) and climbing fibers (CFs) (Sugawara et al., 2013). Interestingly, overall dendritic volume of STIM1 ${ }^{P K O}$ PNs was reduced to a significant extent from $2322.23 \pm 69.48 \mu^{3}$ (WT) to $1840.56 \pm 71.48 \mu^{3}$ $\left(\mathrm{STIM} 1^{\mathrm{PKO}} ; p<0.00005\right.$; Fig. $\left.11 C\right)$. A modest effect was also observed on the dendritic area (Fig. 11D). Total dendritic length remained similar between WT and STIM1 ${ }^{P K O}$ PNs (Fig. 11E). Because this method does not allow reliable tracing of finer dendritic branches, it is possible that changes, beyond those seen in the primary and secondary dendrites, have not been detected in our study. Previous studies have demonstrated the importance of STIM2-mediated neuronal SOCE in maintenance of mushroom spines in hippocampal neurons (Sun et al., 2014). However, spine 


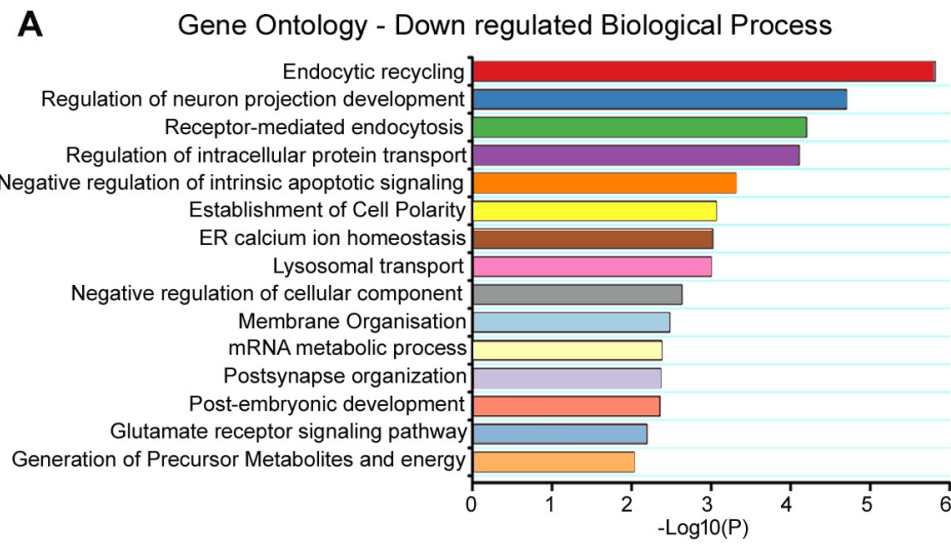

B

Network Plot - Down regulated Biological Process

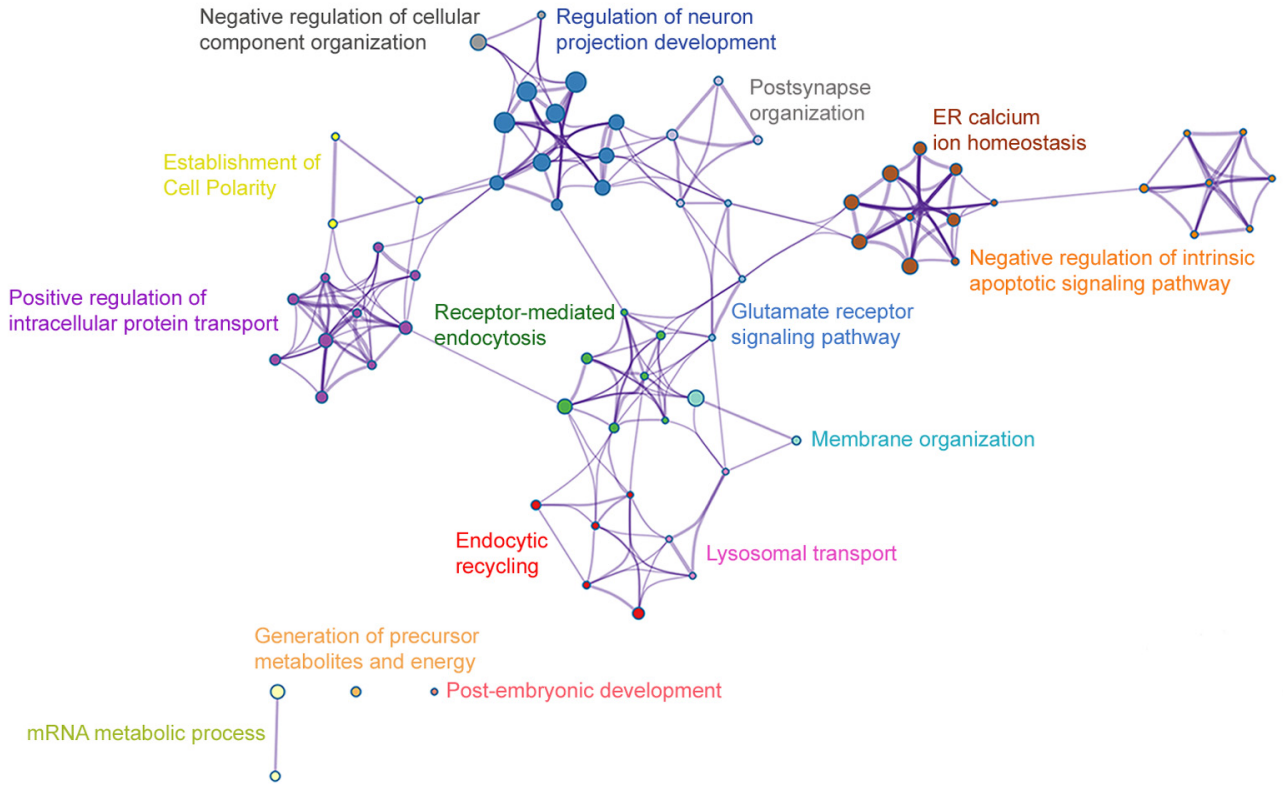

C

$$
\text { Gene Ontology - Up regulated Biological Process }
$$

Regulation of cell cycle process] Regulation of Meiotic Cell Cycle Signal release

Positive regulation of cell development Regulation of cellular carbohydrate metabolic process

Positive regulation of transmembrane transport

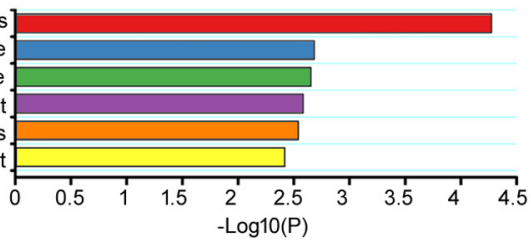

D Network Plot - Up regulated Biological Process
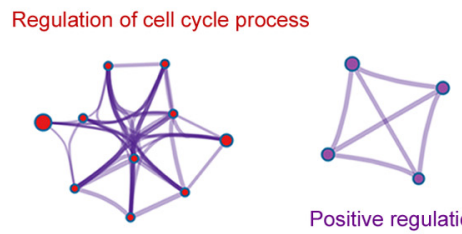

Signal release

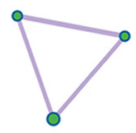

Positive regulation of cell development

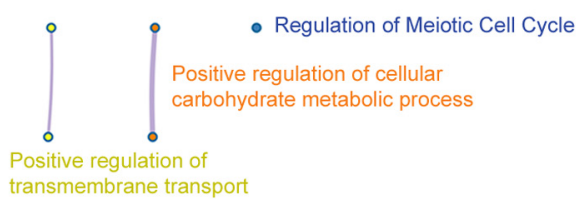

Figure 8. Biological processes affected by the absence of STIM1 in the PNs. $\boldsymbol{A}$, Biological processes enriched among genes that are downregulated in STIM1 KO PNs. $\boldsymbol{B}$, Network analysis of significant biological processes from A. C, Biological processes enriched among genes that are upregulated in STIM1 KO PNs. D, Network analysis of significant biological processes of upregulated genes. In the network plots, each circle node represents $\mathrm{GO}$ terms where its size is proportional to the number of input genes included in the term, and its color represents its cluster identity. Nodes that share common genes are connected by edges. Edge width corresponds to the number of genes that are shared between nodes, and edge length represents the similarity coefficient between nodes. $\mathrm{G} 0$ analysis was performed using Metascape and parameters specific for Mus musculus with $p$ value cutoff as 0.01 , count threshold at 3, and minimum enrichment as 1.5 . Details of $\mathrm{GO}$ terms are provided in Extended Data Figures 8-1 and 8-2.

density at the distal end of the STIM1 ${ }^{\text {PKO }}$ PNs appeared no different from WT (Fig. 11F,G). An estimation of different subtypes of spines in STIM1 ${ }^{P K O}$ PNs would have been informative. However, the resolution of confocal images obtained was insufficient to identify spine subtypes. Moreover, the spine density observed appeared higher than from published data with Golgi staining (Sugawara et al., 2013; Xiao et al., 2020). This discrepancy may be either because of the different methods used or the fact that we 
A Gene Ontology - Down regulated Cellular Components

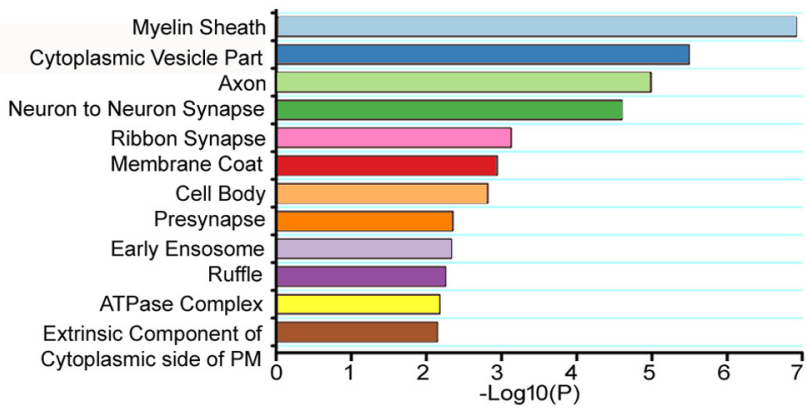

C Gene Ontology - Down regulated KEGG and Reactome Pathway

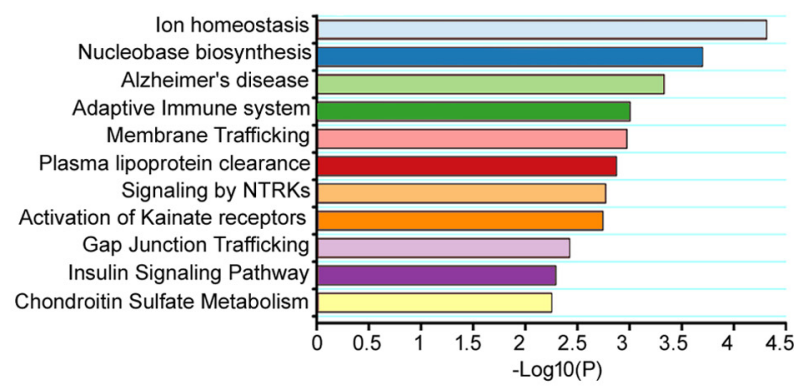

B Network Plot - Cellular Components

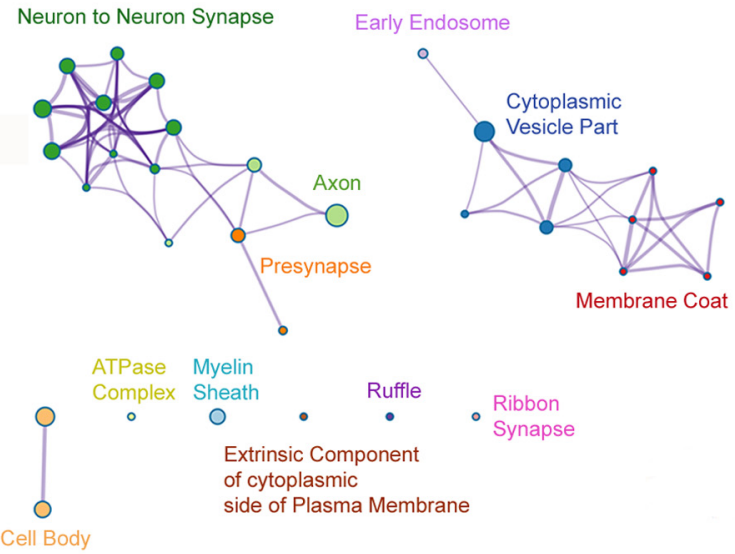

D Network Plot - KEGG and Reactome Pathway

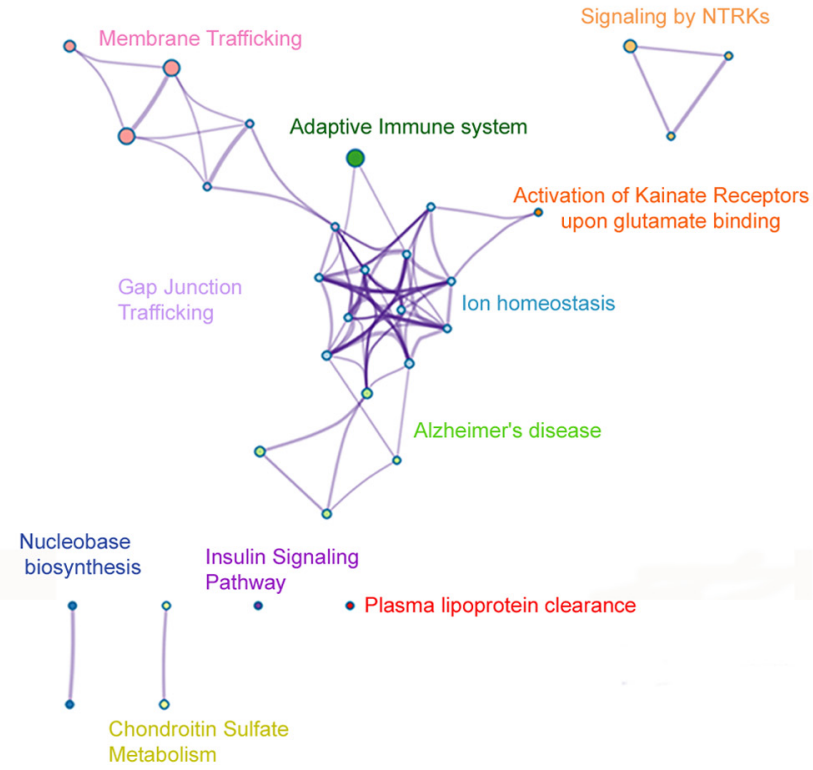

Figure 9. GO analysis of enriched cellular components and KEGG pathway among downregulated genes. $A$, Analysis of enriched cellular components among genes that are downregulated in STIM1 KO PNs. B, Network analysis of significant cellular components from A. C, Enriched KEGG pathway and Reactome analysis of downregulated genes in STIM1 K0 PNs. D, Network analysis of significant KEGG and Reactome pathway from C. G0 analysis was performed using Metascape and parameters specific for Mus musculus with $p$ value cutoff as 0.01 , count threshold at 3 , and minimum enrichment as 1.5. Details of $\mathrm{G} 0$ terms are provided in Extended Data Figures 9-1 and 9-2.

have used older mice for our studies. Our data demonstrate that signaling through STIM1 helps maintain the dendritic arborization and dendritic morphology of PNs, and suggest that altered expression of genes because of loss of STIM1 could be responsible in part for the changes in dendritic morphology.

Loss of STIM1 in PNs enhances climbing fiber innervation of PN dendrites

Appropriate CF-PN synaptic wiring influences information processing and integration essential for motor learning and coordination (Ichikawa et al., 2016). Multiple CFs innervate PNs at birth and subsequently undergo pruning so that a single CF innervates a $\mathrm{PN}$ in mature adults. This extensive pruning of CF-PN synapses continues until postnatal week 3 (Crepel, 1982; Hashimoto et al., 2009; Watanabe and Kano, 2011) and depends on mGluR1 activation during the late phases (Kano et al., 1995, 1997, 1998; Offermanns et al., 1997; Hashimoto et al., 2001). Attenuation of mGluR1 signaling and reduced excitability were observed in PNs of STIM1 $1^{P K O}$ animals (Fig. 6). Consequently, we examined the density and distribution of CF-PN synapses by counting VGLUT2 (vesicular glutamate transporter type 2) puncta along the dendrites of PNs from animals 14 weeks and 1 year of age (Fig. 12). A significant increase in VGLUT2 puncta was observed along the proximal dendrites of STIM1 ${ }^{\text {PKO }}$ PNs in mice 14 weeks of age (Fig. $12 A, B)$, whereas the density of VGLUT2 puncta at the distal dendrites appeared comparable between control and STIM1 ${ }^{\text {PKO }}$ cerebellum (Fig. 12C,D). Interestingly, in animals 1 year of age, the density of VGLUT2 puncta along both the proximal (Fig. 12E,F) and distal dendrites of STIM1 ${ }^{P K O}$ PNs (Fig. 12G,H) increased significantly, suggesting that loss of STIM1 leads to long-term changes in synapse formation extending from 14 weeks to 1 year. Transcriptional profiling data from animals 1 year of age show that genes for endocytic recycling, postsynapse organization, and glutamate receptor signaling, all of which are likely to impact synapse function, are significantly downregulated in STIM1 ${ }^{P K O}$ PNs (Fig. 8A,B). Reduced expression of synaptic components in STIM $1^{P K O}$ PNs may thus be a compensatory mechanism for appropriate loss of synapse elimination, as suggested by excess VGLUT2 puncta in 1-year-old animals. 


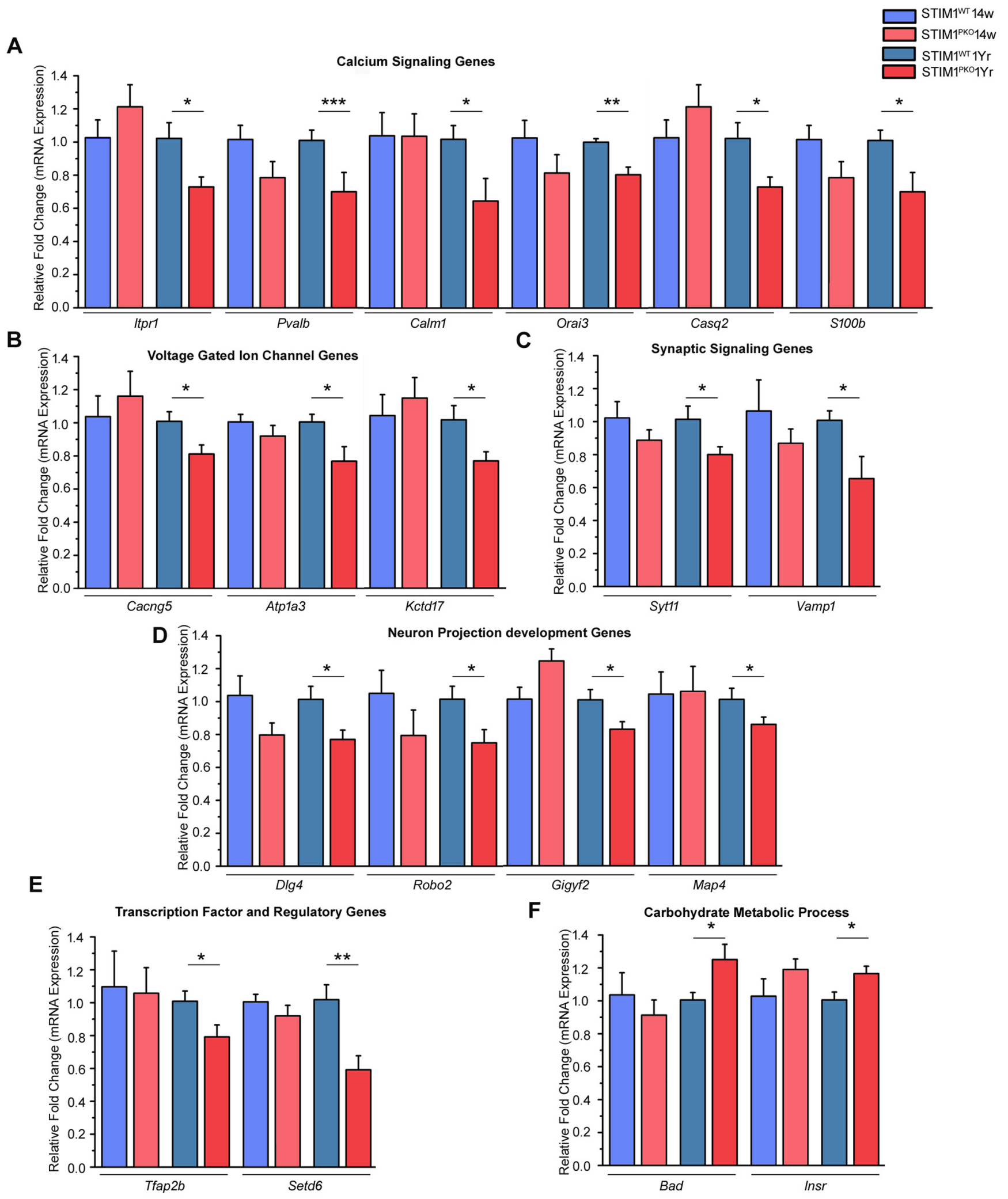

Figure 10. Age-dependent gene expression changes in STMP PKO PNs. Bar graphs of fold changes in expression levels of the indicated genes from biologically significant pathways, such as $(\boldsymbol{A})$ calcium signaling, $(\boldsymbol{B})$ voltage-gated ion channels, $(\boldsymbol{C})$ synaptic signaling, $(\boldsymbol{D})$ neuron projection development, $(\boldsymbol{E})$ transcription factor, and $(\boldsymbol{F})$ carbohydrate metabolic process. Fold changes were normalized to GAPDH. All measurements are by qRT-PCR of CDNA prepared from RNA isolated from micro-dissected PNL $+\mathrm{ML}(n=6)$. Data are mean \pm SEM. ${ }^{*} p<0.05$; ${ }^{* *} p<0.01$; ${ }^{* * *} p<0.001$; two-tailed Student's $t$ test. Pcp2, Purkinje cell protein 2; Stim1, stromal interaction molecule 1; Gabra6, GABA type A receptor subunit alpha6; Itpr1, inositol 1,4,5-trisphosphate receptor 1; Pvalb, parvalbumin; Calm1, calmodulin1; Casq2, calsequestrin 2; Cacng5, calcium voltage-gated channel auxiliary subunit $\gamma 5$; Atp 1a3, ATPase $\mathrm{Na}^{+} / \mathrm{K}^{+}$transporting subunit $\alpha 3$; Kctd17, potassium channel tetramerization domain containing 17; Syt11, synaptotagmin 11; Vamp1, vesicle-associated membrane protein 1; Dlg4, discs large homolog 4; Rob02, roundabout guidance receptor 2; Gigyf2, GRB10-interacting GYF protein 2; Map4, microtubule-associated protein 4; Ifap2b, transcription factor AP-2 $\beta$; Setd6, SET domain containing 6; Bad, Bclll-associated agonist of cell death; Insr, insulin receptor; Gapdh, glyceraldehyde 3-phosphate dehydrogenase. Details of fold change and exact $p$ value are provided in Table 2. 

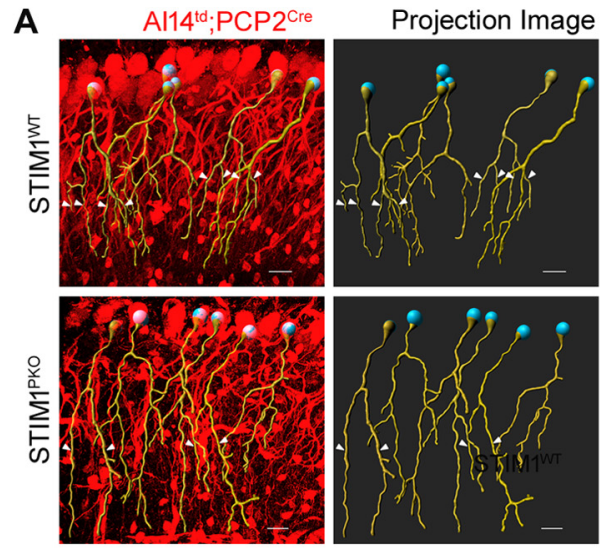

C

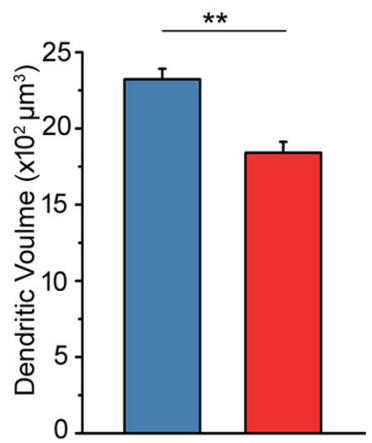

D

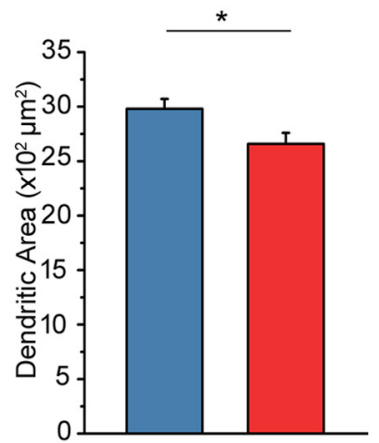

B
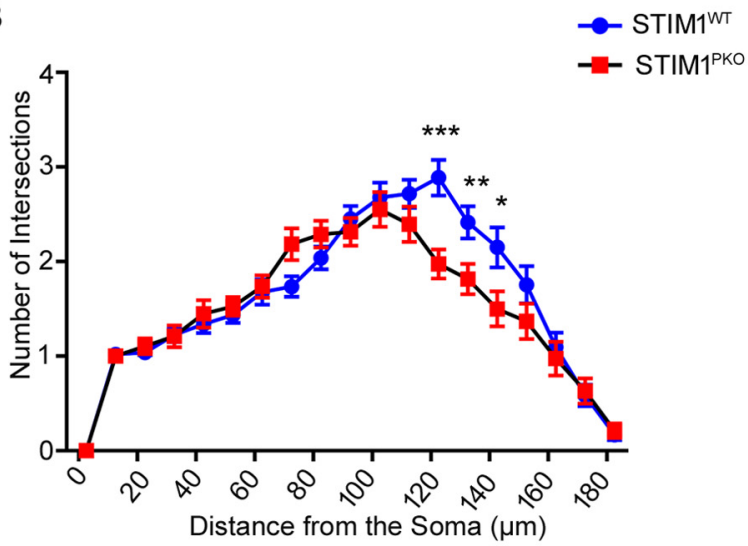

E

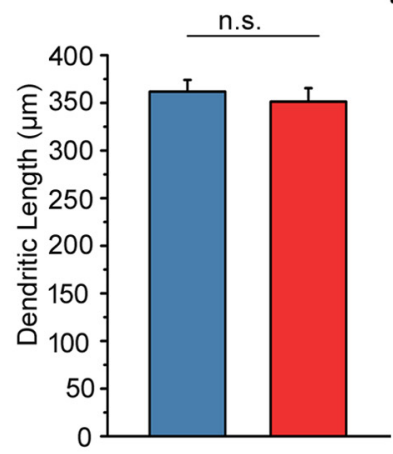

G

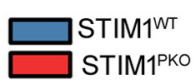

STIM1 $1^{\text {PKO }}$
$\mathbf{F}$
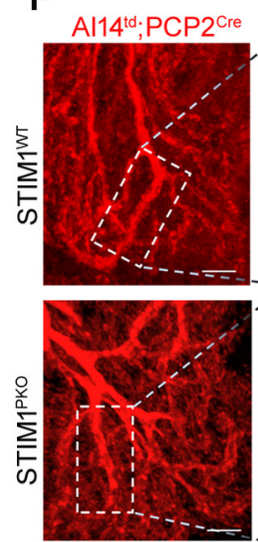

$\mathrm{Al} 14^{\mathrm{td}} ; \mathrm{PCP} 2^{\mathrm{Cre}}$
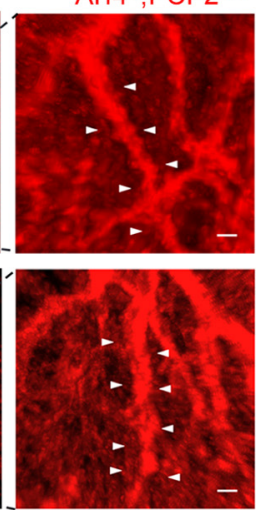

$\mathrm{Al} 14^{\mathrm{td}} ; \mathrm{PCP} 2^{\mathrm{Cre}}$
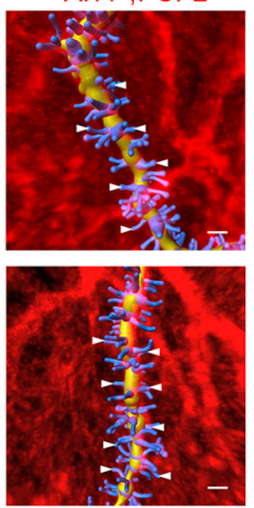
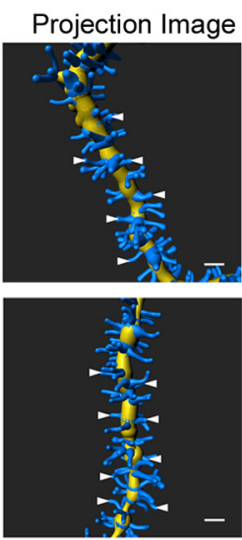

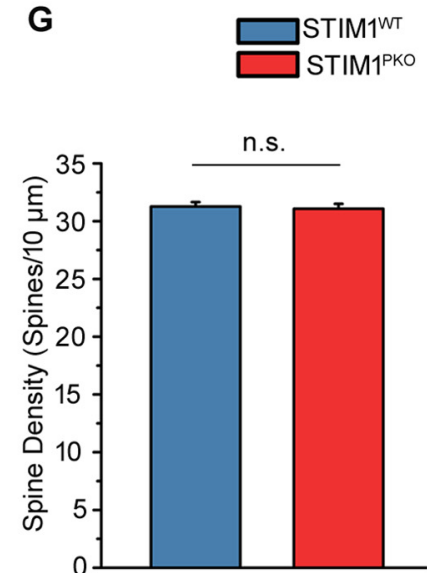

Figure 11. Alteration in dendritic morphology observed in STIM1 KO PNs. A, Confocal analysis of dendritic arborization in PNs of control and STIM1 KO mice using Filament Tracer (Auto Depth) in Imaris software. Confocal images of PN dendrites (left) and their projection image, traced using Imaris (right) are shown. White arrowheads indicate $120 \mu \mathrm{m}$. Scale bar, $20 \mu \mathrm{m}$. $\boldsymbol{B}$, Sholl analysis with number of intersections ( $y$ axis) and distance from the soma (in $\mu \mathrm{m} ; x$ axis) for PN dendrites from control and STIM ${ }^{P K O}$ animals. ${ }^{*} p<0.05 ;{ }^{* *} p<0.01 ;{ }^{* * *} p<0.001 ;$ tw0-way ANOVA with Sidak's multiple comparison test. C, Bar graph with quantification of the total dendritic volume $\left(S T I M 1^{W T}, 2322.24 \pm 69.48 \mu \mathrm{m}^{3} ;\right.$ STIM $^{\text {PKO }}, 1840.56 \pm 71.49 \mu \mathrm{m}^{3} ; p=5.82 \times 10^{-6}$ ) (D) dendritic area $\left(S T I M 1^{W T}, 2979.99 \pm 90.96 \mu \mathrm{m}^{2} ;\right.$ STIM1 $\left.{ }^{\text {PKO }}, 2658.20 \pm 100.96 \mu \mathrm{m}^{2} ; p=0.0202\right)$ and (E) dendritic length (STIM1 ${ }^{W T}, 361.74 \pm 12.36 \mu \mathrm{m} ;$ STIM1 ${ }^{\text {PKO }}, 351.35 \pm 14.18 \mu \mathrm{m}$; $p=0.5821$ ) of control and STIM1 $1^{\text {PKO }}$ dendrites [STIM1 ${ }^{W T}, n=54$; STIM1 ${ }^{\text {PKO }}, n=38$ PNs]. F, Spine morphology on distal dendrites of PNs from STIM1 ${ }^{W T}$ and STIM1 ${ }^{\text {PKO }}$. Confocal images of distal PN dendrites expressing tdTomato (from left; scale bar, $4 \mu \mathrm{m}$ ) followed by enlarged images of the marked regions (scale bar, $2 \mu \mathrm{m}$ ). The enlarged confocal image is followed by an overlay with the corresponding projection image traced using Imaris and the projection image from Imaris analysis (extreme right). White arrowheads indicate some of the spines present on a distal dendrite. $\mathbf{G}$, Bar graph represents the quantitative analysis of spine density (spines $/ 10 \mu \mathrm{m}$ ) along the distal dendrites of PN for the indicated genotype [STIM1 ${ }^{W T}, 31.28 \pm 0.38$ ( $n=16$ PNs); STIM ${ }^{\text {PKO }}, 31.08 \pm 0.43$ $\left(n=14\right.$ PNs); $p=0.7324$ ]. Three mice (age 1 year) were analyzed per group. Data are mean \pm SEM. ${ }^{*} p<0.05 ;{ }^{* *} p<0.01$; two-tailed Student's $t$ test; n.S., not significant..

\section{Discussion}

In this study, we have identified molecular and cellular changes that occur in murine PNs with cell-specific loss of STIM1. Excitability and $\mathrm{Ca}^{2+}$ signaling in response to mGluR1 stimulation are affected early and are concomitant with loss of STIM1 protein (after 12 weeks), whereas changes in gene expression appear to be age-dependent and are evident in older animals.
Older STIM1 ${ }^{P K O}$ mice also exhibit an age-dependent increase in VGLUT2 puncta, which correspond to CF-PN synapses (Fremeau et al., 2001) accompanied by subtle changes in dendritic morphology (Fig. 13). Altered dendritic morphology and excessive CF-PN inputs imply that error encoding during motor learning tasks is likely to be impaired in aged STIMP ${ }^{P K O}$ mice (Nguyen-Vu et al., 2013). This idea requires further testing. The 

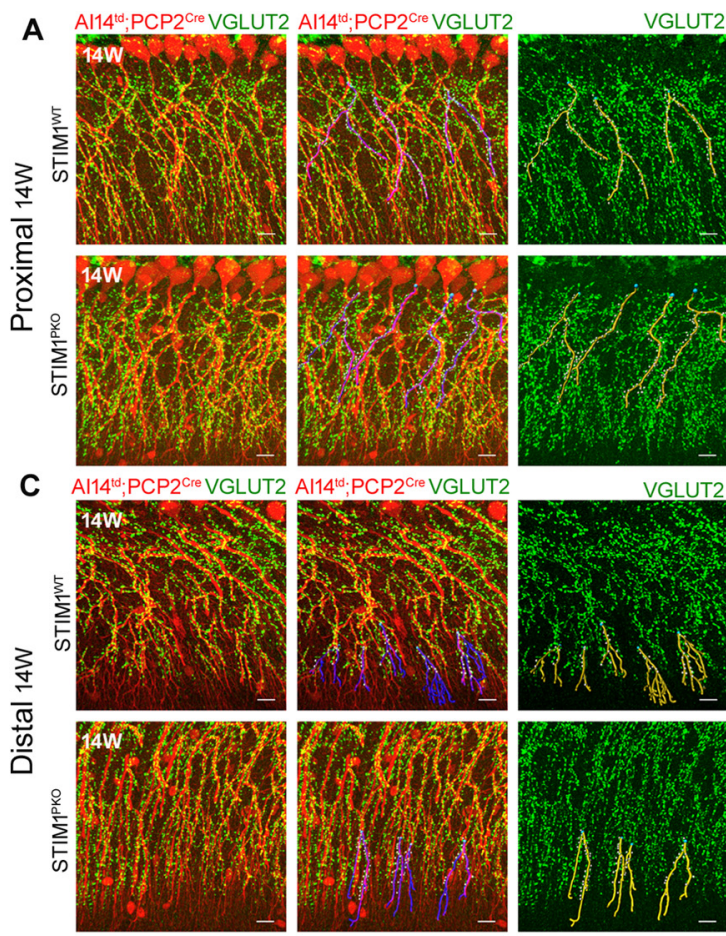

E

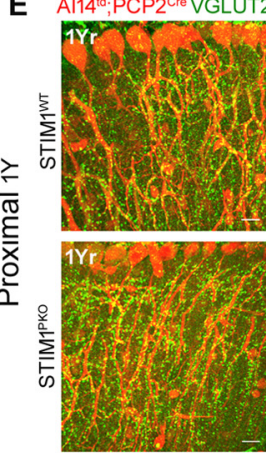

G

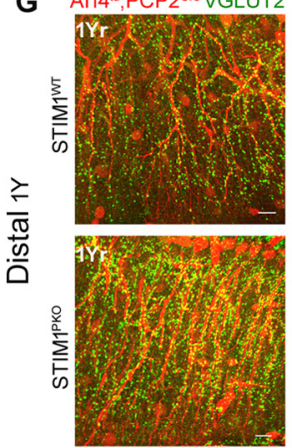

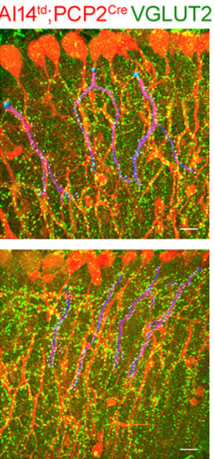

Al14 $4^{\text {tid:PCP2 }}$ Cre VGLUT2
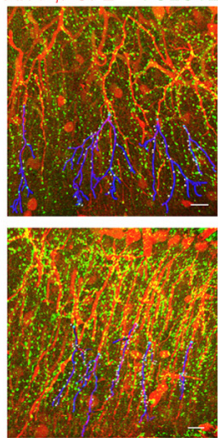
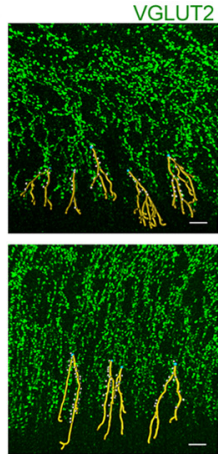

VGLUT2
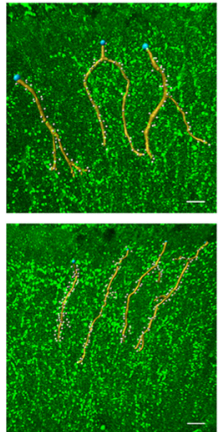

VGLUT2

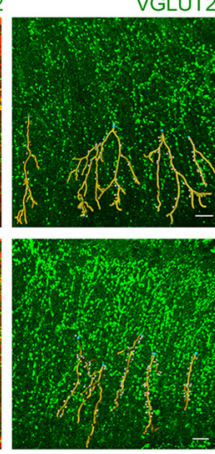

B
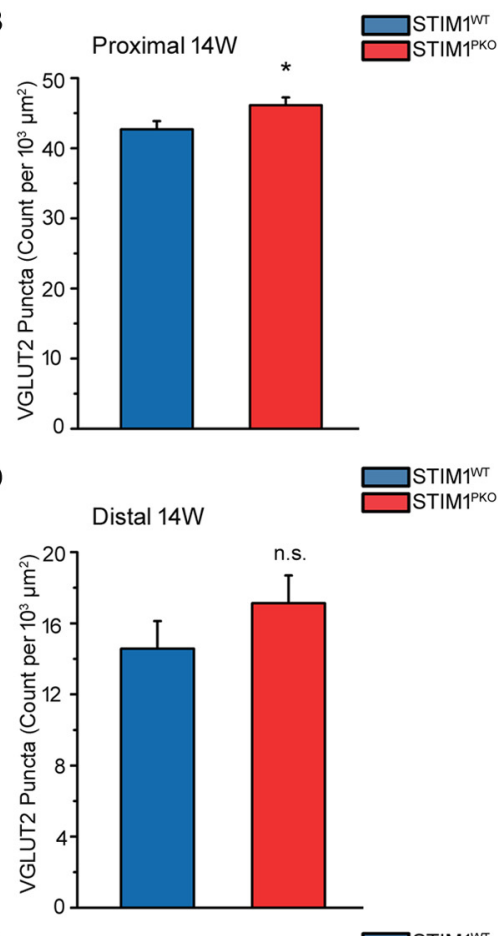

F

Proximal $1 \mathrm{Yr}$
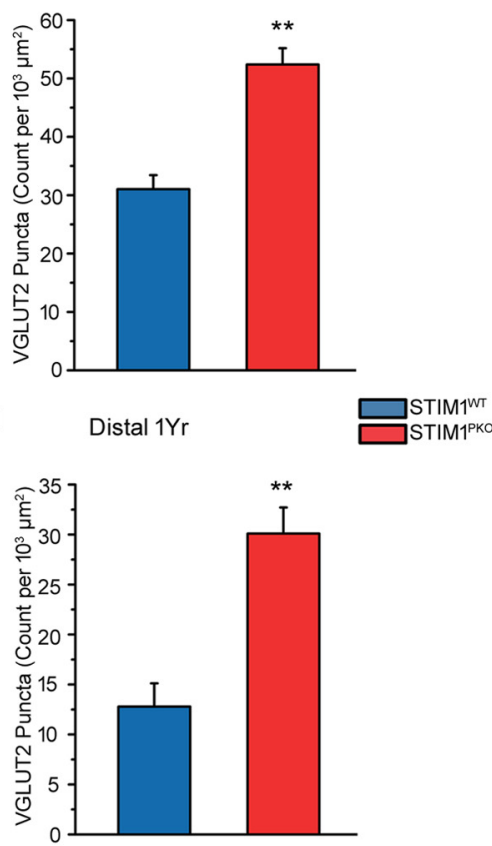

Figure 12. Defects in synaptogenesis in the PNs of STIM1 KO mutants in vivo. Immunohistochemical analysis of CF innervation of PN dendrites in cerebella from STIM1 ${ }^{W T}$ and STIM ${ }^{P K O} 14-$ week- and 1-year-old mice. $A, C, E, G$ Immunostaining of PNs with VGLUT2 puncta (green) and Td tomato expression (red; left), overlay of projection images from Imaris analysis with dendritic filaments marked in blue on the image from the left (middle) and VGLUT2 puncta (green) along with projection images of dendritic filaments from Imaris analysis marked in yellow (right) in mice of the indicated ages and genotypes. Scale bars, $10 \mu \mathrm{m} . \boldsymbol{B}, \boldsymbol{D}, \boldsymbol{F}, \boldsymbol{H}$, Bar graph represents the density of VGLUT2 puncta (count per $10^{3} \mu \mathrm{m}^{2}$ ) at the indicated dendritic regions in young (14 week) and old (1 year) mice. Proximal 14 weeks: STIM1 ${ }^{W T}, 42.70 \pm 1.16 ;$ STM $^{\text {PKO }}, 46.13 \pm 1.11 ; p=0.0363$; distal 14 weeks: STIM7 ${ }^{W T}, 14.57 \pm 1.55 ;$ STIM7 $7^{\text {PKO }}, 17.13 \pm 1.56 ; p=0.2569 ;$ proximal 1 year: STIM1 ${ }^{W T}, 31.02 \pm 2.41 ; S T I M 7^{P K O}, 52.39 \pm 2.80 ; p=4.06 \times 10^{-7}$; distal 1 year: STIM1 ${ }^{W T}, 12.78 \pm 2.32 ; S T I M 7^{P K O}, 30.09 \pm 2.61 ; p=3.87 \times 10^{-5}$. Puncta density quantifications were from 3 mice of each age and genotype and 12 or more PNs from each genotype. Data are mean \pm SEM. ${ }^{*} p<0.05 ;{ }^{* *} p<0.0001$; two-tailed Student's $t$ test; n.S., not significant..

loss of mGluR1 $\mathrm{Ca}^{2+}$ signals in STIM1 ${ }^{\text {PKO }}$ PNs through adult life might result in the increase of CF-PN puncta with age. Based on the observation that parallel changes in gene expression occur and affect multiple synapse components, it is likely that reduced mGluR1 signaling in the PN dendrites sets up a negative feedback loop between reduced synaptic activity, ER-
$\mathrm{Ca}^{2+}$ homeostasis, and changes in gene expression, thus further affecting PN synaptic function and CF-PN synapses with age.

\section{STIM1 and $\mathrm{Ca}^{2+}$ signaling in Purkinje neurons}

Interestingly, within a few weeks of loss of STIM1 from PNs, mGluR1 responses reduce significantly as also the ability to learn 
and perform a motor coordination task (Figs. 4, 6). An important physiological output of mGluR1/IP ${ }_{3} \mathrm{R}$-mediated $\mathrm{Ca}^{2+}$ signaling is LTD of PF-PN synapses. Loss of either mGluR1 or the $\mathrm{IP}_{3} \mathrm{R} 1$ abrogates LTD (Aiba et al., 1994; Inoue et al., 1998; Ichise et al., 2000). LTD requires that the PNs receive within a $100-500 \mathrm{~ms}$ window both repetitive $\mathrm{PF}$ inputs for stimulating mGluR1/IP 3 -mediated $\mathrm{Ca}^{2+}$ release and CF-activated action potentials (Sarkisov and Wang, 2008). Attenuated $\mathrm{Ca}^{2+}$ entry in STIM1 ${ }^{\text {PKO }}$ mice affects refilling of ER stores in PNs, which in turn suppresses mGluR1-stimulated $\mathrm{Ca}^{2+}$ signals and therefore the ability to respond to repetitive $\mathrm{PF}$ inputs (Hartmann et al., 2014). Based on the reduced $\mathrm{KCl}$ responses observed in $\mathrm{PNs}$ of $S T I M 1^{P K O}$ mice, it is likely that $\mathrm{PN}$ response to $\mathrm{CF}$ inputs is also attenuated. The status of LTD in STIM1 $1^{\text {PKO }}$ thus needs further investigation.

Unlike $I P_{3} R 1$ (Sugawara et al., 2013) or mGluR1 mutant mice (Aiba et al., 1994), loss of STIM1 in PNs does not lead to either neurodegeneration or ataxia. STIM $1^{\text {PKO }}$ mice appeared normal under standard cage conditions, and motor learning deficits appear only when they are challenged with a more complex motor task, such as walking on an accelerated rotarod. With age, their ability to perform the motor coordination task deteriorates, but no more than the deterioration found in aging WT mice (Fig. 4F). We did not observe loss of PNs at either 1 year (Fig. 2C) or 1.5 years (Fig. 3C) of age. Thus, cellular and physiological phenotypes of STIM1 ${ }^{P K O}$ mice appear in a milder version of phenotypes in $m G l u R 1$ mutant mice and mice with PN specific KO of the $I P_{3} R 1$ (Sugawara et al., 2013).

Both neuronal and glial calcium homeostasis may be affected in the STIM1 ${ }^{P K O}$ cerebellum

Transcriptomic analysis of PNs from STIM1 ${ }^{P K O}$ mice identified STIM1-dependent mechanisms as essential for maintaining the expression of multiple genes that impact $\mathrm{Ca}^{2+}$ signaling and $\mathrm{Ca}^{2+}$ homeostasis with age (Figs. 7F,G, 8-10). PNs express a range of $\mathrm{Ca}^{2+}$ channels, $\mathrm{Ca}^{2+}$-binding proteins, $\mathrm{Ca}^{2+}$-dependent kinases, and phosphatases that together presumably help maintain cellular $\mathrm{Ca}^{2+}$ homeostasis, regulate various $\mathrm{Ca}^{2+}$-dependent processes, and modulate the multiple inputs received by PNs (Prestori et al., 2019). Among such downregulated genes, the $I P_{3} R 1$ is significant because previous studies have reported downregulation of $I P_{3} R 1$ expression in mouse models for SCAs (Lin et al., 2000; Serra et al., 2004; Crespo-Barreto et al., 2010; Ingram et al., 2016; Stoyas et al., 2020). STIM1 ${ }^{P K O}$ PNs also show reduced expression of a range of $\mathrm{Ca}^{2+}$-binding proteins, including parvalbumin, which is expressed abundantly in PNs (Caillard et al., 2000; Schwaller et al., 2002). PNs from SCA1 patients (Vig et al., 1996) and transgenic mice expressing the human SCA1 causing gene (Vig et al., 1998) also show significant reduction in parvalbumin expression. Also downregulated in STIM1 ${ }^{\text {PKO }} \mathrm{PNs}$ is calmodulin 1, another the EF hand-containing calcium-binding protein that regulates activity of several $\mathrm{Ca}^{2+}$-regulated enzymes, such as $\alpha$ CaMKII and $\beta$ CaMKII required for
Suppressed mGluR1 signaling Reduced excitability

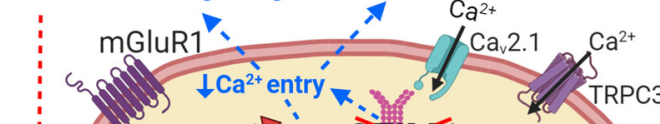

西
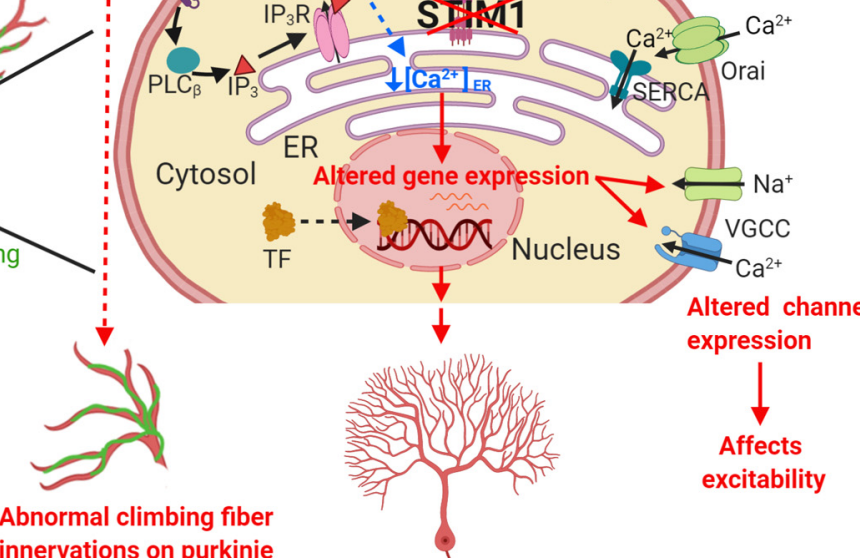

innervations on purkinje neuron dendrites Altered dendritic morphology

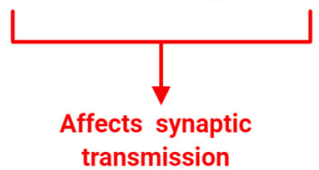

transmission

Figure 13. Schematic representation of age-dependent STIM1 functions in cerebellar PNs. The ER-Ca ${ }^{2+}$ sensor STIM1 lies at the heart of intracellular $\mathrm{Ca}^{2+}$ signaling in PNs. Loss of STIM1 attenuates $\mathrm{Ca}^{2+}$ entry and affects refilling of ER stores, which suppresses mGluR1-stimulated $\mathrm{Ca}^{2+}$ signals and PN excitability. Over time, these changes affect gene expression and Phrases in red represent longer-term changes observed at 1 year. The schematic encapsulates novel findings from this work and from previous studies (Hartmann et al., 2014; Ryu et al., 2017). Model created using Biorender (www.BioRender.com).

cerebellar LTD and motor learning (Hansel et al., 2006; Van Woerden et al., 2009). Calmodulin levels are also reduced in the cerebellar vermis of a spontaneously ataxic mouse (Pogo) (K. Y. Lee et al., 2011).

Downregulated genes for $\mathrm{Ca}^{2+}$-binding proteins include $\mathrm{S} 100 \beta$, which is not expressed to a detectable extent in PNs but is expressed abundantly in the Bergmann glia (Fig. 3D), whose processes enwrap synapses of PN dendrites (Yamada and Watanabe, 2002). Our data demonstrate that changes in $\mathrm{Ca}^{2+}$ homeostasis because of loss of STIM1 in PNs can impact glial gene expression by mechanism(s) that need identification. In the hippocampus, loss of S100B from glial cells affects neuronal plasticity, indicating the significance of reduced S100B on neuronal function and the importance of glia-neuron interactions (Nishiyama et al., 2002).

Gene expression changes observed in PNs from STIM1 ${ }^{P K O}$ mice suggest the existence of specific transcription factors whose activity is affected by altered cellular $\mathrm{Ca}^{2+}$ homeostasis. Our study does not identify such factors; but interestingly, we observed that expression of Setd6 was significantly downregulated in STIM $1^{P K O}$ PNs from mice 1 year of age (Figs. 7F, 10E). SETD6 is an N-lysine methyltransferase that directly methylates RelA (Chang et al., 2011; Levy et al., 2011) and PAK4 (p21-activated kinase 4) (Vershinin et al., 2016). A recent study demonstrated that knockdown of Setd6 interferes with memory consolidation, gene expression patterns, and spine morphology in the hippocampus of rat (Webb et al., 2020). Reduced expression of Setd6 and another transcription factor Tfap2b (Transcription factor AP-2 $\beta$ ) in PNs from STIM1 ${ }^{P K O}$ mice (Figs. $7 F, 10 E$ ) might thus be responsible for some of the altered gene expression patterns observed in STIM1 $1^{\text {PKO }}$ PNs. 


\section{STIM1 in Purkinje neurons impacts expression of multiple genes in common with cerebella from ataxic individuals}

A common feature of a number of downregulated genes, corresponding to different biological processes, is their known effect on maintenance of normal gait and motor coordination. These include Itpr1 (Lin et al., 2000; Serra et al., 2004; Crespo-Barreto et al., 2010; Ingram et al., 2016; Stoyas et al., 2020), Dlg4 (Feyder et al., 2010), Robo2 (Gibson et al., 2014), and Gigyf2 (Giovannone et al., 2009). IP ${ }_{3} R 1$ mutant mice exhibit ataxia and dystonia (Matsumoto et al., 1996; Hisatsune et al., 2013), and human patients with loss or mutation of one copy of the $I P_{3} R 1$ exhibit SCA15, SCA29, or Gillespie's syndrome (Hasan and Sharma, 2020). Dlg4 encodes PSD-95 (postsynaptic density protein 95), a membrane-associated guanylate kinase and a major scaffolding protein in the excitatory postsynaptic density that regulates synaptic strength (Kim and Sheng, 2004; Funke et al., 2005; D. Cheng et al., 2006). Dlg4 KO mice show impaired motor coordination (Feyder et al., 2010). Robo2 is a transmembrane receptor for the secreted molecule Slit2 (Slit homolog 2 protein) and functions during axon guidance and cell migration (Ma and Tessier-Lavigne, 2007; Giovannone et al., 2012). PN-specific Robo2-deficient mice exhibit gait alterations (Gibson et al., 2014). Mice heterozygous for Gigyf2 exhibit motor dysfunction (Giovannone et al., 2009). GO analysis indicates that these genes belong to independent biological processes (Fig. 8A; Extended Data Fig. 8-1). Network analysis (Fig. $8 B$ ) suggests that genes, such as Itpr1, Dlg4, Robo2, and Gigyf2, impact postsynapse organization of PNs and could thus affect synaptic plasticity required for motor learning. In this context, the reduction in dendritic volume in PNs of STIM1 ${ }^{P K O}$ mice (Fig. 11C) is also significant because reduced dendritic volume is observed in mice with $\mathrm{KO}$ of the SCA 5 causing gene $\beta$-III spectrin (Gao et al., 2011). Reduced expression of ion channels and ion pumps (Cacng5, Atp1a3, Kctd17) as well as synaptic transmission-related genes, such as Syt11 and Vamp1 in STIM1 ${ }^{P K O}$ mice (Fig. 10B,C), indicates an effect of STIM1 KO on the density and composition of membrane channels and pumps in PNs.

Disruption of intracellular $\mathrm{Ca}^{2+}$ signaling in PNs has been proposed as a key mechanism in the pathogenesis of SCAs (Liu et al., 2009; Schorge et al., 2010; Kasumu and Bezprozvanny, 2012; Shimobayashi and Kapfhammer, 2017). Previous studies on SCA models identified several major biological pathways in common with STIM ${ }^{P K O}$ analysis, such as calcium signaling, glutamate receptor signaling, and synaptic LTD (Serra et al., 2004; Gatchel et al., 2008; Crespo-Barreto et al., 2010; Ingram et al., 2016). Defective intracellular $\mathrm{Ca}^{2+}$ signaling is also associated with several other neurodegenerative disorders that affect motor coordination, such as Parkinson's disease (Zhou et al., 2016) and Huntington's disease (Wu et al., 2011, 2016; Nekrasov et al., 2016). Pharmaceutical agents that modulate STIM1 function and potentially restore $\mathrm{Ca}^{2+}$ homeostasis could thus function as therapeutics for multiple neurodegenerative disorders associated with dysregulated intracellular $\mathrm{Ca}^{2+}$ signaling.

\section{References}

Airaksinen MS, Eilers J, Garaschuk O, Thoenen H, Konnerth A, Meyer M (1997) Ataxia and altered dendritic calcium signaling in mice carrying a targeted null mutation of the calbindin D28k gene. Proc Natl Acad Sci USA 94:1488-1493.

Aiba A, Kano M, Chen C, Stanton ME, Fox GD, Herrup K, Zwingman TA, Tonegawa S (1994) Deficient cerebellar long-term depression and impaired motor learning in mGluR1 mutant mice. Cell 79:377-388.
Albus S (1971) A theory of cerebellar function. Math Biosci 10:25-61.

Anders S, Huber W (2010) Differential expression analysis for sequence count data. Genome Biol 11:R106.

Anders S, Huber W (2012) Differential expression of RNA-Seq data at the gene level: the DESeq package. Eur Mol Biol Lab 10:1-24.

Anders S, McCarthy DJ, Chen Y, Okoniewski M, Smyth GK, Huber W, Robinson MD (2013) Count-based differential expression analysis of RNA sequencing data using R and Bioconductor. Nat Protoc 8:17651786.

Anders S, Pyl PT, Huber W (2015) HTSeq: a Python framework to work with high-throughput sequencing data. Bioinformatics 31:166-169.

Barski JJ, Dethleffsen K, Meyer M (2000) Cre recombinase expression in cerebellar Purkinje cells. Genesis 28:93-98.

Bauernfeind AL, Barks SK, Duka T, Grossman LI, Hof PR, Sherwood CC (2014) Aerobic glycolysis in the primate brain: reconsidering the implications for growth and maintenance. Brain Struct Funct 219:1149-1167.

Boyden ES, Katoh A, Pyle JL, Chatila TA, Tsien RW, Raymond JL (2006) Selective engagement of plasticity mechanisms for motor memory storage. Neuron 51:823-834.

Burright EN, Clark HB, Servadio A, Matilla T, Feddersen RM, Yunis WS, Duvick LA, Zoghbi HY, Orr HT (1995) SCA1 transgenic mice: a model for neurodegeneration caused by an expanded CAG trinucleotide repeat. Cell 82:937-948.

Caillard O, Moreno H, Schwaller B, Llano I, Celio MR, Marty A (2000) Role of the calcium-binding protein parvalbumin in short-term synaptic plasticity. Proc Natl Acad Sci USA 97:13372-13377.

Chang Y, Levy D, Horton JR, Peng J, Zhang X, Gozani O, Cheng X (2011) Structural basis of SETD6-mediated regulation of the NF-kB network via methyl-lysine signaling. Nucleic Acids Res 39:6380-6389.

Cheng D, Hoogenraad CC, Rush J, Ramm E, Schlager MA, Duong DM, Xu P, Wijayawardana SR, Hanfelt J, Nakagawa T, Sheng M, Peng J (2006) Relative and absolute quantification of postsynaptic density proteome isolated from rat forebrain and cerebellum. Mol Cell Proteomics 5:11581170.

Cheng H, Wang S, Feng R (2016) STIM1 plays an important role in TGF$\beta$-induced suppression of breast cancer cell proliferation. Oncotarget 7:16866-16878.

Clark HB, Burright EN, Yunis WS, Larson S, Wilcox C, Hartman B, Matilla A, Zoghbi HY, Orr HT (1997) Purkinje cell expression of a mutant allele of SCA1 in transgenic mice leads to disparate effects on motor behaviors, followed by a progressive cerebellar dysfunction and histological alterations. J Neurosci 17:7385-7395.

Coesmans M, Sillevis Smitt PA, Linden DJ, Shigemoto R, Hirano T, Yamakawa Y, Van Alphen AM, Luo C, Van der Geest JN, Kros JM, Gaillard CA, Frens MA, De Zeeuw CI (2003) Mechanisms underlying cerebellar motor deficits due to mGluR1-autoantibodies. Ann Neurol 53:325-336.

Crepel F (1982) Regression of functional synapses in the immature mammalian cerebellum. Trends Neurosci 5:266-269.

Crespo-Barreto J, Fryer JD, Shaw CA, Orr HT, Zoghbi HY (2010) Partial loss of ataxin-1 function contributes to transcriptional dysregulation in spinocerebellar ataxia type 1 pathogenesis. Plos Genet 6:e1001021.

Dean P, Porrill J, Ekerot CF, Jörntell H (2010) The cerebellar microcircuit as an adaptive filter: experimental and computational evidence. Nat Rev Neurosci 11:30-43.

De Bartolo P, Florenzano F, Burello L, Gelfo F, Petrosini L (2015) Activitydependent structural plasticity of Purkinje cell spines in cerebellar vermis and hemisphere. Brain Struct Funct 220:2895-2904.

Deb BK, Pathak T, Hasan G (2016) Store-independent modulation of $\mathrm{Ca}^{2+}$ entry through Orai by Septin 7. Nat Commun 7:11751.

Deng W, Wang Y, Liu Z, Cheng H, Xue Y (2014) HemI: a toolkit for illustrating heatmaps. PLoS One 9:e111988.

Feske S (2007) Calcium signalling in lymphocyte activation and disease. Nat Rev Immunol 7:690-702.

Feyder M, Karlsson RM, Mathur P, Lyman M, Bock R, Momenan R, Munasinghe J, Scattoni ML, Ihne J, Camp M, Graybeal C, Strathdee D, Begg A, Alvarez VA, Kirsch P, Rietschel M, Cichon S, Walter H, MeyerLindenberg A, Grant SG, et al. (2010) Association of mouse Dlg4 (PSD95) gene deletion and human DLG4 gene variation with phenotypes relevant to autism spectrum disorders and Williams' syndrome. Am J Psychiatry 167:1508-1517. 
Fremeau RT, Troyer MD, Pahner I, Nygaard GO, Tran CH, Reimer RJ, Bellocchio EE, Fortin D, Storm-Mathisen J, Edwards RH, Francisco S, Blindern PO (2001) The expression of vesicular glutamate transporters defines two. Neuron 31:247-260.

Funke L, Dakoji S, Bredt DS (2005) Membrane-associated guanylate kinases regulate adhesion and plasticity at cell junctions. Annu Rev Biochem 74:219-245.

Gao Y, Perkins EM, Clarkson YL, Tobia S, Lyndon AR, Jackson M, Rothstein JD (2011) $\beta$-III spectrin is critical for development of Purkinje cell dendritic tree and spine morphogenesis. J Neurosci 31:16581-16590.

Gatchel JR, Watase K, Thaller C, Carson JP, Jafar-Nejad P, Shaw C, Zu T, Orr HT, Zoghbi HY (2008) The insulin-like growth factor pathway is altered in spinocerebellar ataxia type 1 and type 7. Proc Natl Acad Sci USA 105:1291-1296.

Gibson DA, Tymanskyj S, Yuan RC, Leung HC, Lefebvre JL, Sanes JR, Chédotal A, Ma L (2014) Dendrite self-avoidance requires cell-autonomous slit/robo signaling in cerebellar Purkinje cells. Neuron 81:10401056.

Giovannone B, Tsiaras WG, De la Monte S, Klysik J, Lautier C, Karashchuk G, Goldwurm S, Smith RJ (2009) GIGYF2 gene disruption in mice results in neurodegeneration and altered insulin-like growth factor signaling. Hum Mol Genet 18:4629-4639.

Giovannone D, Reyes M, Reyes R, Correa L, Martinez D, Ra H, Gomez G, Kaiser J, Ma L, Stein MP, De Bellard ME (2012) Slits affect the timely migration of neural crest cells via robo receptor. Dev Dyn 241:12741288.

Gopurappilly R, Deb BK, Chakraborty P, Hasan G (2018) Stable STIM1 knockdown in self-renewing human neural precursors promotes premature neural differentiation. Front Mol Neurosci 11:178.

Gruszczynska-Biegala J, Pomorski P, Wisniewska MB, Kuznicki J (2011) Differential roles for STIM1 and STIM2 in store-operated calcium entry in rat neurons. PLoS One 6:e19285.

Hachem S, Laurenson AS, Hugnot JP, Legraverend C (2007) Expression of S100B during embryonic development of the mouse cerebellum. BMC Dev Biol 7:17-15.

Hansel C, de Jeu M, Belmeguenai A, Houtman SH, Buitendijk GH, Andreev D, De Zeeuw CII, Elgersma Y (2006) $\alpha$ CaMKII is essential for cerebellar LTD and motor learning. Neuron 51:835-843.

Hartmann J, Dragicevic E, Adelsberger H, Henning HA, Sumser M, Abramowitz J, Blum R, Dietrich A, Freichel M, Flockerzi V, Birnbaumer L, Konnerth A (2008) TRPC3 channels are required for synaptic transmission and motor coordination. Neuron 59:392-398.

Hartmann J, Karl RM, Alexander RP, Adelsberger H, Brill MS, Rühlmann C, Ansel A, Sakimura K, Baba Y, Kurosaki T, Misgeld T, Konnerth A (2014) STIM1 controls neuronal $\mathrm{Ca}^{2+}$ signaling, mGluR1-dependent synaptic transmission, and cerebellar motor behavior. Neuron 82:635-644.

Hasan G, Sharma A (2020) Regulation of neuronal physiology by $\mathrm{Ca}^{2+}$ release through the IP3R. Curr Opin Physiol 17:1-8.

Hashimoto K, Ichikawa R, Takechi H, Inoue Y, Aiba A, Sakimura K, Mishina M, Hashikawa T, Konnerth A, Watanabe M, Kano M (2001) Roles of glutamate receptor $\delta 2$ subunit (GluR $\delta 2)$ and metabotropic glutamate receptor subtype 1 (mGluR1) in climbing fiber synapse elimination during postnatal cerebellar development. J Neurosci 21:9701-9712.

Hashimoto K, Ichikawa R, Kitamura K, Watanabe M, Kano M (2009) Translocation of a "winner" climbing fiber to the Purkinje cell dendrite and subsequent elimination of "losers" from the soma in developing cerebellum. Neuron 63:106-118.

Hekman KE, Gomez CM (2015) The autosomal dominant spinocerebellar ataxias: emerging mechanistic themes suggest pervasive Purkinje cell vulnerability. J Neurol Neurosurg Psychiatry 86:554-561.

Hisatsune C, Miyamoto H, Hirono M, Yamaguchi N, Sugawara T, Ogawa N, Ebisui E, Ohshima T, Yamada M, Hensch TK, Hattori M, Mikoshiba K (2013) IP3R1 deficiency in the cerebellum/brainstem causes basal ganglia-independent dystonia by triggering tonic Purkinje cell firings in mice. Front Neural Circuits 7:156.

Ichikawa R, Miyazaki T, Kano M, Hashikawa T, Tatsumi H, Sakimura K, Mishina M, Inoue Y, Watanabe M (2002) Distal extension of climbing fiber territory and multiple innervation caused by aberrant wiring to adjacent spiny branchlets in cerebellar Purkinje cells lacking glutamate receptor $\delta 2$. J Neurosci 22:8487-8503.

Ichikawa R, Hashimoto K, Miyazaki T, Uchigashima M, Yamasaki M, Aiba A, Kano M, Watanabe M (2016) Territories of heterologous inputs onto
Purkinje cell dendrites are segregated by mglur1-dependent parallel fiber synapse elimination. Proc Natl Acad Sci USA 113:2282-2287.

Ichise T, Kano M, Hashimoto K, Yanagihara D, Nakao K, Shigemoto R, Katsuki M, Aiba A (2000) mGluR1 in cerebellar Purkinje cells essential for long-term depression, synapse elimination, and motor coordination. Science 288:1832-1835.

Ingram $\mathrm{M}$, Wozniak EA, Duvick $\mathrm{L}$, Yang $\mathrm{R}$, Bergmann $\mathrm{P}$, Carson $\mathrm{R}$, O'Callaghan B, Zoghbi HY, Henzler C, Orr HT (2016) Cerebellar transcriptome profiles of ATXN1 transgenic mice reveal SCA1 disease progression and protection pathways. Neuron 89:1194-1207.

Inoue T, Kato K, Kohda K, Mikoshiba K (1998) Type 1 inositol 1,4,5-trisphosphate receptor is required for induction of long-term depression in cerebellar Purkinje neurons. J Neurosci 18:5366-5373.

Ito M (2006) Cerebellar circuitry as a neuronal machine. Prog Neurobiol 78:272-303.

Kaneko M, Yamaguchi K, Eiraku M, Sato M, Takata N, Kiyohara Y, Mishina M, Hirase H, Hashikawa T, Kengaku M (2011) Remodeling of monoplanar Purkinje cell dendrites during cerebellar circuit formation. PLoS One 6:e20108.

Kano M, Hashimoto K, Chen C, Abeliovich A, Aiba A, Kurihara H, Watanabe M, Inoue Y, Tonegawa S (1995) Impaired synapse elimination during cerebellar development in PKC $\gamma$ mutant mice. Cell 83:12231231.

Kano M, Hashimoto K, Kurihara H, Watanabe M, Inoue Y, Aiba A, Tonegawa S (1997) Persistent multiple climbing fiber innervation of cerebellar Purkinje cells in mice lacking mGluR1. Neuron 18:71-79.

Kano M, Hashimoto K, Watanabe M, Kurihara H, Offermanns S, Jiang H, Wu Y, Jun K, Shin HS, Inoue Y, Simon MI, Wu D (1998) Phospholipase $\mathrm{C} \beta 4$ is specifically involved in climbing fiber synapse elimination in the developing cerebellum. Proc Natl Acad Sci USA 95:15724-15729.

Kasumu A, Bezprozvanny I (2012) Deranged calcium signaling in Purkinje cells and pathogenesis in spinocerebellar ataxia 2 (SCA2) and other ataxias. Cerebellum 11:630-639.

Kim E, Sheng M (2004) PDZ domain proteins of synapses. Nat Rev Neurosci 5:771-781.

Koeppen AH (2005) The pathogenesis of spinocerebellar ataxia. Cerebellum 4:62-73.

Koeppen AH, Ramirez RL, Bjork ST, Bauer P, Feustel PJ (2013) The reciprocal cerebellar circuitry in human hereditary ataxia. Cerebellum 12:493503.

Lalonde J, Saia G, Gill G (2014). Store-operated calcium entry regulates transcription factor Sp4 in resting neurons. Sci Signal 7:1-14.

Landry CF, Ivy GO, Dunn RJ, Marks A, Brown IR (1989) Expression of the gene encoding the $\beta$-subunit of S- 100 protein in the developing rat brain analyzed by in situ hybridization. Brain Res Mol Brain Res 6:251-262.

Lee KJ, Kim H, Rhyu IJ (2005) The roles of dendritic spine shapes in Purkinje cells. Cerebellum 4:97-104.

Lee KY, Kim JS, Kim SH, Park HS, Jeong Y, Lee N, Kim DK (2011) Altered Purkinje cell responses and calmodulin expression in the spontaneously ataxic mouse, Pogo. Eur J Neurosci 33:1493-1503.

Lein ES, Hawrylycz MJ, Ao N, Ayres M, Bensinger A, Bernard A, Boe AF, Boguski MS, Brockway KS, Byrnes EJ, Chen L, Chen L, Chen TM, Chin MC, Chong J, Crook BE, Czaplinska A, Dang CN, Datta S, Dee NR, et al. (2007) Genome-wide atlas of gene expression in the adult mouse brain. Nature 445:168-176.

Levy D, Kuo AJ, Chang Y, Schaefer U, Kitson C, Cheung P, Espejo A, Zee BM, Liu CL, Tangsombatvisit S, Tennen RI, Kuo AY, Tanjing S, Cheung R, Chua KF, Utz PJ, Shi X, Prinjha RK, Lee K, Garcia BA, et al. (2011) SETD6 lysine methylation of RelA couples GLP activity at chromatin to tonic repression of NF- $\kappa$ B signaling. Nat Immunol 12:29-36.

Lin X, Antalffy B, Kang D, Orr HT, Zoghbi HY (2020) Polyglutamine expansion down-regulates specific neuronal genes before pathologic changes in SCA1. Nat Neurosci 3:157-163.

Liou J, Kim ML, Won DH, Jones JT, Myers JW, Ferrell JE, Meyer T (2005) STIM is a Ca ${ }^{2+}$ sensor essential for $\mathrm{Ca}^{2+}$ store- depletion-triggered $\mathrm{Ca}^{2+}$ influx. Curr Biol 15:1235-1241.

Liu J, Tang TS, Tu H, Nelson O, Herndon E, Huynh DP, Pulst SM, Bezprozvanny I (2009) Deranged calcium signaling and neurodegeneration in spinocerebellar ataxia type 2. J Neurosci 29:9148-9162.

Love MI, Huber W, Anders S (2014) Moderated estimation of fold change and dispersion for RNA-seq data with DESeq2. Genome Biol 15:1-21. 
Ma L, Tessier-Lavigne M (2007) Dual branch-promoting and branch-repelling actions of Slit/Robo signaling on peripheral and central branches of developing sensory axons. J Neurosci 27:6843-6851.

Maffezzini C, Calvo-Garrido J, Wredenberg A, Freyer C (2020) Metabolic regulation of neurodifferentiation in the adult brain. Cell Mol Life Sci 77:2483-2496.

Mao X, Yang SH, Simpkins JW, Barger SW (2007) Glutamate receptor activation evokes calpain-mediated degradation of Sp3 and Sp4, the prominent Sp-family transcription factors in neurons. J Neurochem 100:13001314.

Matsumoto M, Nakagawa T, Inoue T, Nagata E, Tanaka K, Takano H, Minowa O, Kuno J, Sakakibara S, Yamada M, Yoneshima H, Miyawaki A, Fukuuchi Y, Furuichi T, Okano H, Mikoshiba K, Noda T (1996) Ataxia and epileptic seizures in mice lacking type 1 inositol 1,4,5-trisphosphate receptor. Nature 379:168-171.

McKay BE, Turner RW (2005) Physiological and morphological development of the rat cerebellar Purkinje cell. J Physiol 567:829-850.

Namikawa K, Dorigo A, Zagrebelsky M, Russo G, Kirmann T, Fahr W, Dübel S, Korte M, Köster RW (2019) Modeling neurodegenerative spinocerebellar ataxia type 13 in zebrafish using a Purkinje neuron specific tunable coexpression system. J Neurosci 39:3948-3969.

Nekrasov ED, Vigont VA, Klyushnikov SA, Lebedeva OS, Vassina EM, Bogomazova AN, Chestkov IV, Semashko TA, Kiseleva E, Suldina LA, Bobrovsky PA, Zimina OA, Ryazantseva MA, Skopin AY, Illarioshkin SN, Kaznacheyeva EV, Lagarkova MA, Kiselev SL (2016) Manifestation of Huntington's disease pathology in human induced pluripotent stem cell-derived neurons. Mol Neurodegener 11:27.

Nguyen-Vu TD, Kimpo RR, Rinaldi JM, Kohli A, Zeng H, Deisseroth K, Raymond JL (2013) Cerebellar Purkinje cell activity drives motor learning. Nat Neurosci 16:1734-1736.

Nishiyama H, Knöpfel T, Endo S, Itohara S (2002) Glial protein S100B modulates long-term neuronal synaptic plasticity. Proc Natl Acad Sci USA 99:4037-4042

Offermanns S, Hashimoto K, Watanabe M, Sun W, Kurihara H, Thompson RF, Inoue Y, Kano M, Simon MI (1997) Impaired motor coordination and persistent multiple climbing fiber innervation of cerebellar Purkinje cells in mice lacking G $\alpha$ q. Proc Natl Acad Sci USA 94:14089-14094.

Ogura H, Matsumoto M, Mikoshiba K (2001) Motor discoordination in mutant mice heterozygous for the type 1 inositol 1,4,5-trisphosphate receptor. Behav Brain Res 122:215-219.

Oh-Hora M, Yamashita M, Hogan PG, Sharma S, Lamperti E, Chung W, Prakriya M, Feske S, Rao A (2008) Dual functions for the endoplasmic reticulum calcium sensors STIM1 and STIM2 in T cell activation and tolerance. Nat Immunol 9:432-443.

Ohtani Y, Miyata M, Hashimoto K, Tabata T, Kishimoto Y, Fukaya M, Kase D, Kassai H, Nakao K, Hirata T, Watanabe M, Kano M, Aiba A (2014) The synaptic targeting of mGluR1 by its carboxyl-terminal domain is crucial for cerebellar function. J Neurosci 34:2702-2712.

Pathan M, Keerthikumar S, Ang CS, Gangoda L, Quek CY, Williamson NA, Mouradov D, Sieber OM, Simpson RJ, Salim A, Bacic A, Hill AF, Stroud DA, Ryan MT, Agbinya JI, Mariadason JM, Burgess AW, Mathivanan S (2015) FunRich: an open access standalone functional enrichment and interaction network analysis tool. Proteomics 15:2597-2601.

Perkins E, Suminaite D, Jackson M (2016) Cerebellar ataxias: $\beta$-III spectrin's interactions suggest common pathogenic pathways. J Physiol 594:46614676.

Prestori F, Moccia F, D’Angelo E (2019) Disrupted calcium signaling in animal models of human spinocerebellar ataxia (SCA). Int J Mol Sci 21:216.

Richhariya S, Jayakumar S, Abruzzi K, Rosbash M, Hasan G (2017) A pupal transcriptomic screen identifies Ral as a target of store-operated calcium entry in Drosophila neurons. Sci Rep 7:42586.

Robinson KJ, Watchon M, Laird AS (2020) Aberrant cerebellar circuitry in the spinocerebellar ataxias. Front Neurosci 14:707.

Robinson MD, Oshlack A (2010) A scaling normalization method for differential expression analysis of RNA-seq data. Genome Biol 11:R25.

Robinson MD, McCarthy DJ, Smyth GK (2010) edgeR: a Bioconductor package for differential expression analysis of digital gene expression data. Bioinformatics 26:139-140

Roos J, DiGregorio PJ, Yeromin AV, Ohlsen K, Lioudyno M, Zhang S, Safrina O, Kozak JA, Wagner SL, Cahalan MD, Veliçelebi G, Stauderman KA (2005) STIM1, an essential and conserved component of store-operated $\mathrm{Ca}^{2+}$ channel function. J Cell Biol 169:435-445.
Rossi M, Perez-Lloret S, Doldan L, Cerquetti D, Balej J, Millar Vernetti P, Hawkes M, Cammarota A, Merello M (2014) Autosomal dominant cerebellar ataxias: a systematic review of clinical features. Eur J Neurol 21:607-615.

Ryu XC, Jang XD, Jung XD, Kim XY, Shim XH, Ryu H, Lee Y, Linden XD, Worley PF, Kim XS (2017) STIM1 regulates somatic $\mathrm{Ca}^{2+}$ signals and intrinsic firing properties of cerebellar Purkinje neurons. J Neurosci 37:8876-8894.

Sarkisov DV, Wang SS (2008) Order-dependent coincidence detection in cerebellar Purkinje neurons at the inositol trisphosphate receptor. J Neurosci 28:133-142.

Schorge S, van de Leemput J, Singleton A, Houlden H, Hardy J (2010) Human ataxias: a genetic dissection of inositol triphosphate receptor (ITPR1)-dependent signaling. Trends Neurosci 33:211-219.

Schwaller B, Meyer M, Schiffmann S (2002) "New" functions for "old" proteins: the role of the calcium-binding proteins calbindin D-28k, calretinin and parvalbumin, in cerebellar physiology. Cerebellum 1:241-258.

Serra HG, Byam CE, Lande JD, Tousey SK, Zoghbi HY, Orr HT (2004) Gene profiling links SCA1 pathophysiology to glutamate signaling in Purkinje cells of transgenic mice. Hum Mol Genet 13:2535-2543.

Seyednasrollah F, Laiho A, Elo LL (2015) Comparison of software packages for detecting differential expression in RNA-seq studies. Brief Bioinform 16:59-70.

Shimobayashi E, Kapfhammer JP (2017) Calcium signaling, PKC gamma, IP3R1 and CAR8 link spinocerebellar ataxias and Purkinje cell dendritic development. Curr Neuropharmacol 16:151-159.

Smitt PS, Kinoshita A, De Leeuw B, Moll W, Coesmans M, Jaarsma D, Henzen-Logmans S, Vecht C, De Zeeuw C, Sekiyama N, Nakanishi S, Shigemoto R (2000) Paraneoplastic cerebellar ataxia due to autoantibodies against a glutamate receptor. N Engl J Med 342:21-27.

Skibinska-Kijek A, Wisniewska MB, Gruszczynska-Biegala J, Methner A, Kuznicki J (2009) Immunolocalization of STIM1 in the mouse brain. Acta Neurobiol Exp (Wars) 69:413-428.

Somasundaram A, Shum AK, McBride HJ, Kessler JA, Feske S, Miller RJ, Prakriya M (2014) Store-operated CRAC channels regulate gene expression and proliferation in neural progenitor cells. J Neurosci 34:91079123.

Steiner P (2019) Brain fuel utilization in the developing brain. Ann Nutr Metab 75 [Suppl 1]:8-18.

Stoyas CA, Bushart DD, Switonski PM, Ward JM, Alaghatta A, Tang MB, Niu C, Wadhwa M, Huang H, Savchenko A, Gariani K, Xie F, Delaney JR, Gaasterland T, Auwerx J, Shakkottai VG, La Spada AR (2020) Nicotinamide pathway-dependent Sirtl activation restores calcium homeostasis to achieve neuroprotection in spinocerebellar ataxia type 7 . Neuron 105:630-644.

Sugawara T, Hisatsune C, Le TD, Hashikawa T, Hirono M, Hattori M, Nagao S, Mikoshiba K (2013) Type 1 inositol trisphosphate receptor regulates cerebellar circuits by maintaining the spine morphology of Purkinje cells in adult mice. J Neurosci 33:12186-12196.

Sun S, Zhang H, Liu J, Popugaeva E, Xu NJ, Feske S, White CL, Bezprozvanny I (2014) Reduced synaptic STIM2 expression and impaired store-operated calcium entry cause destabilization of mature spines in mutant presenilin mice. Neuron 82:79-93.

Tabata T, Sawada S, Araki K, Bono Y, Furuya S, Kano M (2000) A reliable method for culture of dissociated mouse cerebellar cells enriched for Purkinje neurons. J Neurosci Methods 104:45-53.

Trapnell C, Pachter L, Salzberg SL (2009) TopHat: discovering splice junctions with RNA-Seq. Bioinformatics 25:1105-1111.

Van Woerden GM, Hoebeek FE, Gao Z, Nagaraja RY, Hoogenraad CC, Kushner SA, Hansel C, De Zeeuw CI, Elgersma Y (2009) $\beta$ CaMKII controls the direction of plasticity at parallel fiber-Purkinje cell synapses. Nat Neurosci 12:823-825.

Venkiteswaran G, Hasan G (2009) Intracellular $\mathrm{Ca}^{2+}$ signaling and storeoperated $\mathrm{Ca}^{2+}$ entry are required in Drosophila neurons for flight. Proc Natl Acad Sci USA 106:10326-10331.

Vershinin Z, Feldman M, Chen A, Levy D (2016) PAK4 methylation by setd6 promotes the activation of the $\mathrm{wnt} / \beta$-catenin pathway. J Biol Chem 291:6786-6795.

Vig PJ, Fratkin JD, Desaiah D, Currier RD, Subramony SH (1996) Decreased parvalbumin immunoreactivity in surviving Purkinje cells of patients with spinocerebellar ataxia-1. Neurology 47:249-253. 
Vig PJ, Subramony SH, Burright EN, Fratkin JD, McDaniel DO, Desaiah D, Qin Z (1998) Reduced immunoreactivity to calcium-binding proteins in Purkinje cells precedes onset of ataxia in spinocerebellar ataxia-1 transgenic mice. Neurology 50:106-113.

Watanabe M, Kano M (2011) Climbing fiber synapse elimination in cerebellar Purkinje cells. Eur J Neurosci 34:1697-1710.

Webb WM, Irwin AB, Pepin ME, Henderson BW, Huang V, Butler AA, Herskowitz JH, Wende AR, Cash AE, Lubin FD (2020) The SETD6 methyltransferase plays an essential role in hippocampus-dependent memory formation. Biol Psychiatry 87:577-587.

Watase K, Weeber EJ, Xu B, Antalffy B, Yuva-Paylor L, Hashimoto K, Kano M, Atkinson R, Sun Y, Armstrong DL, Sweatt JD, Orr HT, Paylor R, Zoghbi HY (2002) A long CAG repeat in the mouse Scal locus replicates SCA1 features and reveals the impact of protein solubility on selective neurodegeneration. Neuron 34:905-919.

Wu J, Shih HP, Vigont V, Hrdlicka L, Diggins L, Singh C, Mahoney M, Chesworth R, Shapiro G, Zimina O, Chen X, Wu Q, Glushankova L,
Ahlijanian M, Koenig G, Mozhayeva GN, Kaznacheyeva E, Bezprozvanny I (2011) Neuronal store-operated calcium entry pathway as a novel therapeutic target for Huntington's disease treatment. Chem Biol 18:777-793.

Wu J, Ryskamp DA, Liang X, Egorova P, Zakharova O, Hung G, Bezprozvanny I (2016) Enhanced store-operated calcium entry leads to striatal synaptic loss in a Huntington's disease mouse model. J Neurosci 36:125-141.

Xiao R, Zhong H, Li X, Ma Y, Zhang R, Wang L, Zang Z, Fan X (2020) Abnormal cerebellar development is involved in dystonia-like behaviors and motor dysfunction of autistic BTBR mice. Front Cell Dev Biol 8:231.

Yamada K, Watanabe M (2002) Cytodifferentiation of Bergmann glia and its relationship with Purkinje cells. Anat Sci Int 77:94-108.

Zhou Q, Yen A, Rymarczyk G, Asai H, Trengrove C, Aziz N, Kirber MT, Mostoslavsky G, Ikezu T, Wolozin B, Bolotina VM (2016) Impairment of PARK14-dependent $\mathrm{Ca}^{2+}$ signalling is a novel determinant of Parkinson's disease. Nat Commun 7:10332 